\title{
COMO O DIREITO PENSA: EM BUSCA DE UMA EPISTEMOLOGIA CONSTRUTIVISTA DO DIREITO ${ }^{1}$
}

\author{
HOW THE LAW THINKS: TOWARD A CONSTRUCTIVIST \\ EPISTEMOLOGY OF LAW ${ }^{2}$
}

\author{
Recebimento: 9 jun. 2021 \\ Aceitação: 3 ago. 2021
}

Gunther Teubner (autor)

Prof. Dr. Dr. h.c. (Fachbereich 1 - Rechtswissenschaft)

Afiliação institucional: Goethe University Frankfurt am Main (Frankfurt am Main, Hessen, Deutschland)

Homepage: https://bit.ly/3rRQEZQ

Email: G.teubner@jur.uni-frankfurt.de

Lui Martinez Laskowski (tradutor)

Bacharel em Direito

Afiliação institucional: Universidade Federal do Paraná - UFPR - (Curitiba, PR, Brasil) Lattes iD: http://lattes.cnpq.br/4551553911134700

Email: luimlask@gmail.com

Angela Couto Machado Fonseca (tradutora)

Doutora em Filosofia do Direito

Afiliação institucional: Universidade Federal do Paraná - UFPR - (Curitiba, PR, Brasil)

Lattes iD: http://lattes.cnpq.br/9891009099511623

Email: fonseca_angela@yahoo.com.br

Como citar este trabalho / How to cite this work (informe a data atual de acesso / inform the current date of access):

TEUBNER, Gunther. Como o direito pensa: em busca de uma epistemologia construtivista do direito. Revista da Faculdade de Direito UFPR, Curitiba, v. 66, n. 2, p. 213-251, maio/ago. 2021. ISSN 2236-7284. Disponível em: https://revistas.ufpr.br/direito/article/view/81411. Acesso em: 30 ago. 2021. DOI: http://dx.doi.org/10.5380/rfdufpr.v66i2.81411. Tradução: Lui Martinez Laskowski e Angela Couto Machado Fonseca. Título original: How the Law Thinks: Toward a Constructivist Epistemology of Law. Inclui bibliografia.

1 Tradução para o português a partir de original em inglês (original: TEUBNER, G. How the Law Thinks: Toward a Constructivist Epistemology of Law. Law \& Society Review, [s. l.], v. 23, n. 5, p. 727-757, 1989. doi:10.2307/3053760) [N. do E.].

2 Por críticas úteis, gostaria de agradecer a Zenon Bankowski, Klaus Eder, Michael Donnelly, Reiner Grundmann, Christian Joerges, Wolfgang Krohn, Giandomenico Majone, Neil MacCormick, David Nelken, Helga Nowotny, Alessandro Pizzorno, Joyce Reese, Gerhard Roth, Philip Selznick e Sean Smith. 


\section{JAGUADARTE}

Era briluz. As lesmolisas touvas Roldavam e relviam nos gramilvos. Estavam mimsicais as pintalouvas, E os momirratos davam grilvos.

Professor de direito americano comentando sobre Niklas Luhmann, “The Unity of the Legal System”.

Estudiosos de direito e sociedade europeus e americanos aparentemente têm problemas em se comunicar uns com os outros. Invocar a autoridade de Lewis Carroll em um artigo de teoria do direito indica quão sérios são os problemas; afinal, "Jaguadarte" ", a famosa "Estrofe de Poesia AngloSaxônica"”, significa “semanas de desgraça” em sua versão original em alemão ${ }^{5}$. Inextricavelmente envolvido na interpretação da poesia está um certo Hermann von Schwindel.

Essa falta de compreensão mútua é um fenômeno recente. A comunicação ainda era fácil quando o regime das teorias intermediárias de Merton governava o estudo do direito e sociedade. Houve um consenso de que, a partir da observação paciente do direito real no mundo real, um corpo de teorias não metafísicas e não especulativas evoluiria. Esse consenso refletiu-se numa linguagem comum, sóbria, profissional e compreensível. No entanto, com o "Retorno da Grande Teoria" e a invasão do pós-estruturalismo, da teoria crítica, da teoria do discurso e da autopoiese no mundo sociojurídico, o discurso unificado do direito e sociedade está novamente dividindo-se em diferentes províncias culturais. O resultado deplorável é uma fragmentação de linguagens teóricas, o “Jaguadarte” da teoria sociojurídica.

A obscuridade da linguagem é o comentário crítico mais comum sobre as recentes modas da teoria europeia, sejam de Paris, Frankfurt ou Bielefeld. Diz-se que a linguagem é excessivamente complexa - muitas vezes incompreensível -, e que o é para esconder trivialidades por trás de uma cortina de fumaça de palavras modernas, como “discurso jurídico”, "racionalidade comunicativa” e “autopoiese jurídica”.

É claro que más traduções desempenham um papel infeliz nessa troca de ideias. Além disso, os contextos culturais nacionais ainda são tão diversos hoje em dia que o transplante de uma teoria

3 No original, Jabberwocky, poema nonsense de Lewis Carroll presente em Through the Looking-Glass and What Alice Found There. Utilizamos a tradução poética de Augusto Luís Browne de Campos [N. do T.].

4 CARROLL, 1855, 1871, p. 191.

5 SCOTT, R. (alias Chatterton). The Jabberwock Traced to its True Source. Macmillan's Magazine, [s. l.], fevereiro de 1872.

6 SKINNER, 1985 
de um contexto para outro leva a um grau de incompreensibilidade que só pode ser gradualmente reduzido com uma explicação cuidadosa. Também se deve admitir que, às vezes, as idiossincrasias pessoais dos teóricos tornam seus textos desnecessariamente difíceis de entender. No entanto, o núcleo do problema está em outro lugar. É uma questão de saber se a linguagem é complexa o suficiente para corresponder à complexidade do assunto. As novas teorias sobre o direito afirmam construir realidades sociojurídicas que não podem ser adequadamente expressadas pela linguagem comum. Para elas, ceder às exigências de fácil compreensão seria comprometer o conteúdo de sua mensagem.

Tomemos um exemplo concreto. No contexto da autopoiese do direito, vários autores estão trabalhando em uma nova teoria da pessoa jurídica7. Em sua linguagem, “a realidade social de uma pessoa jurídica deve ser encontrada na coletividade: a autodescrição socialmente vinculante de um sistema de ação organizado como uma ligação cíclica de identidade e ação.” O quê? Mais Jaguadarte? As organizações pensam? Como elas podem ter a capacidade de se descrever? Vinculação entre identidade e ação? Tudo isso soa como aquelas mistificações infames de coletividades. Obviamente, as coletividades não atuam, apenas os indivíduos, e apenas as ações individuais são agregadas à ação coletiva. Então, por que não retornar à formulação mais sóbria e compreensível de Max Weber sobre o mesmo assunto?

Esses conceitos de entidades coletivas têm significado nas mentes das pessoas individuais, em parte como algo realmente existente, em parte como algo com autoridade normativa. Isso é verdade não apenas para juízes e funcionários, mas também para pessoas comuns. Os atores, portanto, em parte, orientam sua ação em relação a elas e, nesse papel, tais ideias têm uma influência causal poderosa, muitas vezes decisiva, no curso da ação dos indivíduos reais (WEBER, 1978, p. 14).

Mas isso ainda é o mesmo? Certamente, agora podemos entender facilmente as palavras. A mensagem, no entanto, está perdida. A novidade reside nas seguintes questões, que partem ponto a ponto das visões de mundo invocadas pela linguagem comum:

1. As organizações não consistem em indivíduos humanos como membros, mas de comunicados - mais precisamente, de decisões - como seus elementos autoconstituídos.

2. Organizações “pensam.” É através da comunicação interna que elas constroem realidades sociais próprias, independentemente das construções de realidade de seus membros individuais. Em resumo, as organizações são sujeitos epistêmicos.

7 Ator coletivo, personalidade corporativa; cf. LUHMANN, 1984, p. 270 et seq.; TEUBNER, 1988 a, p. 130 et seq.; KNYPHAUSEN, 1988, p. 120 et seq.; HUTTER, 1989, cap. 4; LADEUR, 1989b; VARDARO, 1990. 
3. As organizações não são per se capazes de ação coletiva. Elas se transformam em atores coletivos conforme constituem, comunicativamente, sua identidade.

4. A capacidade de ação coletiva emerge quando as organizações, em sua identidade coletiva, produzem ações e, vice-versa, quando a ação organizacional produz a identidade coletiva da organização.

Obviamente, essas quatro questões sugerem uma realidade social da pessoa jurídica que está muito além dos territórios bem conhecidos das teorias de personalidade corporativa baseadas em ficção, grupo ou ente ${ }^{8}$.

Esse exemplo deve ter deixado claro que o problema de comunicação acima mencionado não se deve à obscuridade da linguagem utilizada, mas à capacidade limitada de nossa linguagem de expressar a construção de realidades sociais só recentemente percebidas. Isso, pelo menos, é o que as novas teorias sobre direito - pós-estruturalismo, teoria crítica e autopoiese - têm em comum. É verdade que Michel Foucault, Jürgen Habermas e Niklas Luhmann “roldam e relvem nos gramilvos”, mas o fazem porque imaginam realidades sociais cuja reconstrução claramente ultrapassa os limites da linguagem comum. O que os torna aparentemente incompreensíveis é sua desgarrada radical de premissas epistemológicas profundamente enraizadas no pensamento contemporâneo sobre direito e sociedade, particularmente do que Pizzorno $^{9}$ polemicamente chama de reificação ${ }^{10}$ de uma “metafísica cotidiana” - realismo epistemológico e individualismo metodológico. Embora o pósestruturalismo, a teoria crítica e a teoria da autopoiese desenvolvam visões bastante diferentes sobre o direito contemporâneo, eles convergem em seu antirrealismo e anti-individualismo ${ }^{11}$.

Deve-se acrescentar que o antirrealismo não significa idealismo epistemológico, e o antiindividualismo não significa holismo/coletivismo metodológico. Não somos confrontados com um ressurgimento das antigas dicotomias realismo/idealismo e individualismo/coletivismo que dominaram os debates sobre a teoria jurídica na primeira metade do século XX. Não é nem Kelsen nem Duguit quem está na agenda da teoria do direito hoje. Em vez disso, no retorno da Grande Teoria, o realismo epistemológico é transformado em um novo construtivismo epistemológico, e os agentes

8 Para a discussão em curso em relação a essas teorias clássicas, cf. HORWITZ, 1985; DAN-COHEN, 1986; SCHANE, 1987; ROOS, 1988.

9 PIZZORNO, 1989.

10 Parece-nos que, ao menos nesse contexto, a "reificação" de Pizzorno é usada como sinônimo de "surgimento", e não “coisificação", como é mais comum em autores de línguas latinas [N. do T.].

11 Dada a orientação humanista da teoria crítica, pode parecer estranho caracterizar essa teoria como anti-individualista. No entanto, não estamos falando de opções político-morais, mas de construções teóricas. Em um sentido tríplice, essa teoria é anti-individualista: (1) em sua crítica do individualismo metodológico nas teorias de atores econômicos e racionais; (2) na substituição de teorias monológicas da formação de normas por formas dialógicas; e (3) na localização do discurso no centro da cognição, em vez de no sujeito epistemológico clássico (cf. "razão comunicativa versus razão centrada no sujeito” em HABERMAS, 1987a, cap. 11; HABERMAS, 1984, cap. 3 em geral). 
do individualismo metodológico são substituídos por construtos, como o discurso, a autorreflexão social e a auto-organização. O que essa reorientação radical da teoria social significa para o direito?

Para o direito, o ponto crucial é a combinação tanto da mudança na epistemologia quanto da nova percepção da individualidade: o construtivismo exclui a ingênua suposição de realidade de que os atores humanos, por meio de suas ações intencionais, constituem os elementos básicos da sociedade. A partir dessa combinação, seguem-se as principais teses deste artigo:

1. Sob uma epistemologia social construtivista, as percepções da realidade do direito não podem ser equiparadas a uma realidade social de alguma forma correspondente, "lá fora”. Pelo contrário, é o direito como um sujeito epistêmico autônomo que constrói uma realidade social própria.

2. Não são os indivíduos humanos, com suas ações intencionais, que produzem o direito como um artefato cultural. Pelo contrário, é o direito como um processo comunicativo que, por meio de suas operações jurídicas, produz atores humanos como artefatos semânticos.

3. Uma vez que a sociedade contemporânea é caracterizada de um lado por uma fragmentação em diferentes epistèmes, e do outro lado pela interferência mútua entre tais epistèmes, o discurso jurídico é capturado numa "armadilha epistêmica”. A dependência e independência simultâneas em relação a outros discursos sociais é a razão pela qual o direito contemporâneo oscila permanentemente entre posições de autonomia e heteronomia cognitiva.

Essa “construção social da realidade” aparentemente se tornou, depois de Berger e Luckmann (1966), sabedoria reconhecida na sociologia ${ }^{12}$. No entanto, nossas três teses mostram que há uma versão mais profunda da epistemologia social do que normalmente se compreende em relação à forma como instituições sociais, comunidades científicas e culturas de laboratório influenciam a percepção individual. Há mais na epistemologia social do que os “interesses” dos agentes sociais responsáveis pela manipulação do conhecimento ${ }^{13}$. As três novas teorias sob consideração aqui - pósestruturalismo, teoria crítica e teoria da autopoiese - radicalizaram a noção do "social” em "cognição social”, de uma forma que vale a pena examinar a fundo em nosso contexto de cognição jurídica. Qual é o significado preciso da afirmação um tanto ambígua de que “o direito constitui uma realidade autônoma”? Similarmente, o que significa dizer que o indivíduo é uma mera construção da sociedade e do direito? E, acima de tudo, como o direito “pensa”?

12 Cf. BLOOR, 1976; LATOUR; WOOLGAR, 1979; KNORR-CETINA, 1984; GILBERT; MULKAY, 1984; COLLINS, 1985; FULLER, 1988.

13 BARNES, 1974. 


\section{DISCURSO E AUTOPOIESE}

É reconfortante, porém, e uma fonte de profundo alívio pensar que o homem é apenas uma invenção recente, uma figura que ainda não tem dois séculos, uma nova ruga em nosso conhecimento, e que ele desaparecerá de novo assim que esse conhecimento descobrir uma nova forma (FOUCAULT, 1974, p. xxiii).

Não apenas o direito e a economia estão irritados com a provocação antirrealista e antiindividualista de Michel Foucault; a maioria das correntes sociológicas que influenciam o pensamento jurídico moderno se sentem desconfortáveis com a descentralização do assunto pelo pósestruturalismo. Sob a enorme influência dos "pais fundadores" do individualismo metodológico, Hayek $^{14}$ e Popper ${ }^{15}$, a realidade quasi-natural dos atores humanos individuais é assumida pelas teorias econômicas e sociais contemporâneas, tais como teorias de microfundamentos ${ }^{16}$ e teorias de escolha racional $^{17}$, que exigem que qualquer fenômeno coletivo seja reduzido a ações intencionais de indivíduos humanos.

De maneira análoga, a redução dos macrofenômenos sociais a características de indivíduos é quase axiomática para o behaviorismo sociológico ${ }^{18}$. A realidade do indivíduo atuante é uma suposição fundamental também para as teorias sociológicas sobre o direito na tradição da sociologia interpretativa de Max Weber. "Afinal, as ações dos indivíduos formam a sociedade"19. Mesmo sociólogos que buscam abordagens estruturalistas e sistêmicas se sentem compelidos a corrigi-las com uma infusão de individualismo ${ }^{20}$.

O fato de que mesmo os autores jurídicos críticos que são profundamente influenciados pelas ideias de Foucault e entusiasticamente assumem suas mensagens políticas se recusam a traçar as consequências epistemológicas é indicativo do caráter epidêmico da síndrome do indivíduorealidade. Duncan Kennedy, em sua recente análise da indeterminação jurídica ${ }^{21}$, revela um viés altamente individualista para o sujeito jurídico reflexivo e os aspectos comunicativos da lei. Assim, no que tange às reflexões e considerações estratégicas do juiz individual, ele está tão longe de uma análise do discurso quanto seus adversários “liberais”. Robert Gordon ${ }^{22}$ rejeita explicitamente as

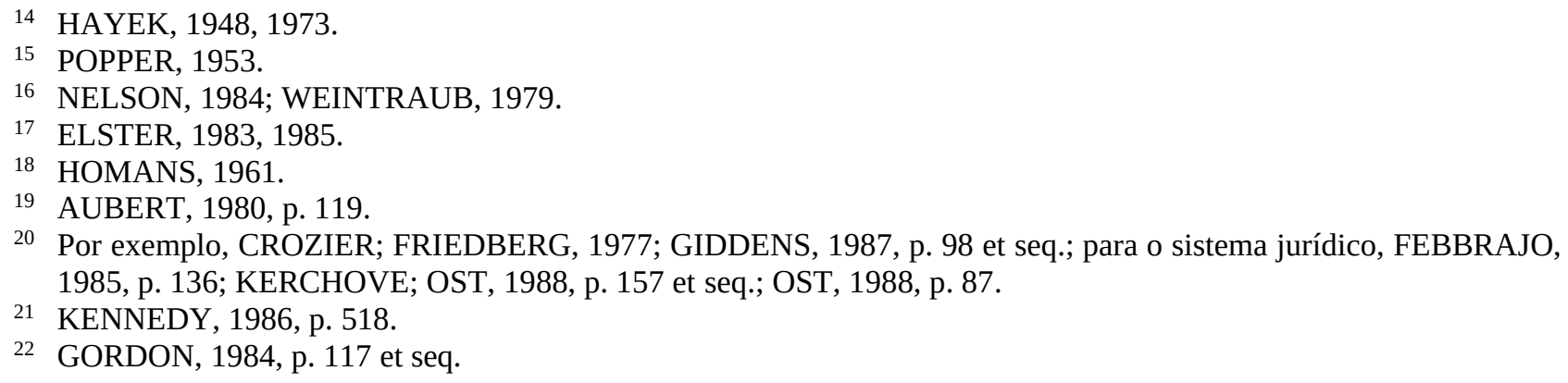


tendências anti-individualistas no estruturalismo e pós-estruturalismo como se sabotassem as intenções humanistas do pensamento jurídico crítico $^{23}$.

O que torna essa combinação de realismo e individualismo no pensamento jurídico contemporâneo tão viável não é tanto sua inerente virtude, mas a falta de alternativas confiáveis. As alternativas tradicionais - idealismo epistemológico e coletivismo metodológico - são vistas como problemáticas, e com razão. Mas será mesmo que as únicas alternativas disponíveis são aquelas que partem de pressupostos idealistas-coletivistas radicais, como se "essas estruturas impessoais tivessem vida própria e os seres humanos fossem escravos das necessidades desse ciclo de vida, construindo ou demolindo conforme o Espírito do Mundo dita ${ }^{24 ” ? ~}$

Como discutirei nas páginas seguintes, existem alternativas aos predominantes modos de pensar (realista e individualista). Visando ao movimento contemporâneo difuso em direção à “construção social da realidade” e à “descentralização do sujeito”, gostaria de destacar três teóricos que contribuíram para uma compreensão mais profunda da cognição sociojurídica e que representam ao mesmo tempo as vertentes intelectuais mais importantes da Europa Ocidental: Michel Foucault (pós-estruturalismo), Jürgen Habermas (teoria crítica) e Niklas Luhmann (teoria da autopoiese). O que eles têm em comum é substituir o indivíduo autônomo não por entidades supraindividuais, mas por processos comunicativos. Diferem, no entanto, em sua identificação da nova unidade cognitiva. Na versão de Habermas da teoria crítica, teorias correspondentistas da verdade são derrubadas por teorias consensuais, e a “intersubjetividade” toma o lugar do sujeito epistêmico.

Foucault e Luhmann são ainda mais radicais em seu desencantar do indivíduo humano. Para Foucault, o indivíduo humano nada mais é do que uma construção efêmera de uma constelação de poder-discurso historicamente contingente, que dita a epistème de uma época cronológica. Luhmann separa completamente os processos psíquicos dos sociais e percebe o indivíduo humano na sociedade como um artefato comunicativo, como um produto da auto-observação da autopoiese social. Os novos sujeitos epistêmicos são sistemas sociais autopoiéticos.

23 Há exceções importantes entre os estudiosos críticos que desenvolvem alternativas sérias ao individualismo predominante, sobretudo em Thomas Heller (1984, 1988) e David Kennedy (1985). No entanto, essas exceções confirmam nossa regra: é a língua deles, até mesmo em seus próprios círculos intelectuais, que agoniza com a síndrome de Jaguadarte.

24 GORDON, 1984, p. 117. 


\section{JÜRGEN HABERMAS: INTERSUBJETIVIDADE E CONSENSO}

Para desenvolver uma epistemologia do direito que realmente mereça seu nome, três mudanças importantes em nossa percepção do direito e da sociedade têm de ser feitas. Primeiro, do realismo ao construtivismo; segundo, da construção individual à construção social da realidade; e terceiro, do direito como um sistema normativo ao direito como um sujeito epistêmico. Enquanto a primeira leva a certa modificação de posições kantianas, as outras duas mudanças abrem novos caminhos na teoria sociológica e jurídica. A segunda mudança revela os fundamentos sociais da cognição de uma maneira mais radical do que a sociologia do conhecimento tradicional jamais fez, e a terceira atribui às práticas discursivas do direito a produção de uma realidade social autônoma.

Nessa reorientação da cognição social e jurídica, a teoria da racionalidade comunicativa de Habermas ${ }^{25}$ desempenha um papel importante. O conceito-chave de “discurso racional” de Habermas destaca o papel crucial do procedimento na cognição empírica e normativa e, ao mesmo tempo, sua “pragmática universal” leva em conta a dimensão social na cognição moral e legal, contra uma epistemologia predominantemente individualista.

Habermas rejeita as teorias tradicionais correspondentistas da verdade (de Aristóteles a Tarski), segundo as quais as afirmações são verdadeiras se corresponderem a uma realidade externa. Em vez disso, ele segue uma teoria consensual da verdade, que declara como critério de verdade o consenso "potencial” de todos os participantes do discurso ${ }^{26}$. Esse movimento, é claro, cria a necessidade de identificar um critério independente para distinguir entre o verdadeiro e o falso consenso. Passando por uma sequência de diferentes critérios, Habermas finalmente o encontra na pressuposição de uma “situação de fala ideal” que em si mesma é definida por certas características formais e procedimentais ${ }^{27}$.

É essa procedimentalização do critério de verdade que tornou a teoria do discurso de Habermas tão importante para o direito ${ }^{28}$. Ela torna o discurso teórico-empírico das ciências diretamente comparável ao discurso prático-normativo da política, na moral e no direito: suas reivindicações de validade dependem da retidão do procedimento ${ }^{29}$. Além disso, essa procedimentalização abre o caminho para um repensar da modernidade do direito em que a tese de

\footnotetext{
5 HABERMAS, 1971a, 1971b, 1974, 1975, 1984, 1987a, 1987b, 1988.

HABERMAS, 1971b, p. 123, 1973, p. 211.

HABERMAS, 1984, cap. 3.

28 Cf., por exemplo, ALEXY, 1978, p. 219 et seq.; GÜNTHER, 1988.

29 HABERMAS, 1984, cap. 3.
} 
Max Weber sobre a materialização do direito formal é substituída por conceitos de procedimentalização do direito ${ }^{30}$.

A outra principal contribuição de Habermas para uma epistemologia do direito é levar em conta o elemento social na cognição empírica e normativa. Sua filosofia atribui "autoridade epistêmica” não mais ao sujeito autônomo, mas à comunidade comunicativa ${ }^{31}$. Enquanto a epistemologia tradicional situa a cognição exclusivamente na consciência do sujeito (empírico ou transcendental), Habermas reconhece que a cognição é basicamente um processo comunicativo. A “intersubjetividade” toma o lugar do sujeito epistêmico kantiano. É o consenso autêntico da comunidade comunicativa - e não a consciência do indivíduo autônomo - que determina a verdade em questões cognitivas e normativas. Assim, a famosa pergunta de Kant que buscava "as condições para que a cognição fosse possível” é redirecionada das condições de consciência para as de comunicação. Até o transcendentalismo se torna socializado: o novo a priori é representado pela “situação de fala ideal”, cuja pressuposição é uma condição da possibilidade de comunicação ${ }^{32}$.

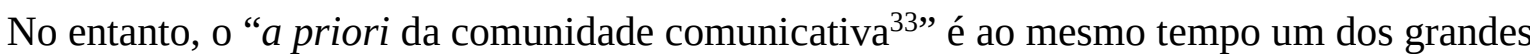
problemas dessa teoria. Com a apriorização de certas características da comunicação, Habermas tenta escapar dos "paradoxos da autorreferência"34 que necessariamente emergem de sua hierarquia de justificação discursiva. O núcleo da teoria de Habermas está na autoaplicação de práticas discursivas: os procedimentos do discurso só podem ser justificados por discursos cujos procedimentos, por sua vez, devem ser justificados pelo discurso ${ }^{35}$. Para evitar a regressão ao infinito ou a circularidade argumentativa, Habermas recorre ao transcendentalismo comunicativo.

Intimamente relacionadas à fundação transcendentalista do discurso racional estão as ambiguidades da "intersubjetividade” que representam o outro problema não resolvido na cognição social em Habermas. O que se entende por “intersubjetividade”? Elementos ou relação? Consciência ou comunicação? Processos psíquicos ou sociais? O sujeito epistêmico de Habermas oscila entre essas duas posições sem nunca encontrar sua identidade em nenhum dos dois mundos ${ }^{36}$. Parece que Habermas tenta novamente evitar os paradoxos da autorreferência no discurso, desta vez mudando o

30 FREY, 1989, p. 55 et seq.; GÜNTHER, 1988; HABERMAS, 1985, p. 215 et seq., 1987c, p. 1; JOERGES, 1989; LADEUR, 1989a; PREUSS, 1989; WIETHÖLTER, 1985, 1986.

31 HABERMAS, 1983, p. 26, 1988, p. 63 et seq., p. 80.

32 HABERMAS, 1971b, p. 136; 1983, p. 53, 1984, cap. 3.

33 APEL, 1973, 1988; BAHLER, 1985.

34 BARWISE; ETCHEMENDY, 1987; KRIPPENDORFF, 1984; QUINE, 1976; WORMELL, 1958.

35 O problema da regressão ao infinito ou circularidade na teoria da justificação discursiva de Habermas é talvez mais claramente expresso em HABERMAS, 1971b, p. 123 et seq., 1973, p. 255 et seq.

36 Para a controvérsia da intersubjetividade versus comunicação, ver HABERMAS, 1987a, cap. 12, 1988, p. 95 et seq.; LUHMANN, 1986c, p. 41 et seq. 
referencial do sistema. Se o discurso pode ser fundado no discurso apenas recursivamente, não é necessário que ele seja fundado na consciência humana?

\section{MICHEL FOUCAULT: DISCURSO E EPISTÈME}

As ideias de Foucault sobre discurso e poder podem ser lidas como uma radicalização da posição epistemológica de Habermas. De fato, Foucault ataca diretamente o que acabamos de descrever como os principais problemas não resolvidos na teoria de Habermas: (i) o fundamento do discurso em um a priori comunicativo e (ii) o papel ambíguo da consciência individual na intersubjetividade. A principal contribuição de Foucault para uma epistemologia social é libertar o conceito central de "discurso”, desprendendo-o de qualquer fundamento transcendental ou psíquico. Claro, isso não o salva das armadilhas de autorreferência. A fuga de Foucault é, ao mesmo tempo, o ponto mais famoso e mais fraco de sua teoria - a onipresença do poder.

O ponto de partida de Foucault é construtivista: a realidade não é algo externo à cognição, sendo constituída, “construída” pela própria cognição. Contudo, em nítido contraste com a tradição clássica, não é a consciência individual do sujeito que constitui a realidade. Tampouco é a intersubjetividade, como em Habermas, o resultado comunicativo da interação entre os atores humanos.

Esse resultado, para o autor, é o “discurso” - uma cadeia de eventos linguísticos, anônima, impessoal e livre de intenções ${ }^{37}$. Deve-se acrescentar que essa não é uma posição estruturalista ${ }^{38}$. O discurso, na teoria de Foucault, é muito mais rico do que a atuação de signos abstratos do estruturalismo. É prática social, não estrutura social; é parole, não langue. Os elementos básicos do discurso não são signos, mas enunciados, énoncés, isto é, o uso social da linguagem que constrói a realidade. A tarefa da análise do discurso não consiste, nas palavras de Foucault, em "tratar os discursos como grupos de signos (elementos significantes referentes a conteúdos ou representações), mas como práticas que sistematicamente formam o objeto de que falam ${ }^{39}$ ”. O discurso é tanto evento quanto estrutura, "uma corrente de eventos linguísticos no espaço e no tempo, bem como uma organização altamente seletiva de eventos linguísticos ${ }^{40}$ ”. E é essa prática social historicamente contingente do discurso que dita a epistème de uma certa época, definindo as condições para a

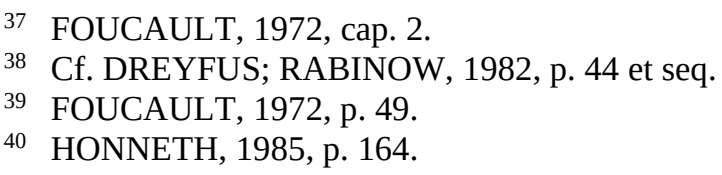


possibilidade de cognição, não de uma maneira universal atemporal, mas temporalmente, concretamente, localmente ${ }^{41}$.

Essa epistemologia social radical não tem lugar para a consciência individual e para as ações intencionais dos sujeitos humanos e não precisa de uma fundação apriorística. O sujeito humano não é mais o autor do discurso. Exatamente o oposto: o discurso produz o sujeito humano como um artefato semântico ${ }^{42}$. Ao mesmo tempo, as formações discursivas são historicamente contingentes, carecendo de qualquer fundamento a priori. Toda sociedade tem sua própria ordem de verdade, sua própria política da verdade.

Ora, seria uma consequência desse modo de pensar que as formações discursivas, essas práticas sociais altamente autônomas, determinariam os critérios para sua própria transformação. Dreyfus e Rabinow, por exemplo, veem claramente essa autorreferencialidade necessária como uma condição para a mudança estrutural dos discursos: já que “ele está comprometido com a visão de que as práticas discursivas são autônomas e determinam seu próprio contexto... ele deve localizar o poder produtivo revelado pelas práticas discursivas nas regularidades dessas mesmas práticas. O resultado é a estranha noção de regularidades que se regulam ${ }^{43}$ ”. Foucault, no entanto, para antes desses paradoxos da autorreferência. Ele se afasta das consequências necessárias de seu próprio construto e introduz o conceito de poder para externar as relações autorreferenciais. Em seu pensamento posterior, ele desiste da ideia de ‘discurso autônomo como o novo sujeito epistêmico’ e recorre à onipresença do poder como uma base quase transcendental das práticas discursivas ${ }^{44}$.

\section{NIKLAS LUHMANN: CONSTRUTIVISMO E AUTOPOIESE}

Os paradoxos de autorreferência parecem ser o principal obstáculo ao desenvolvimento de uma epistemologia autenticamente social. Habermas e Foucault desenvolveram importantes contribuições, mas as consequências radicais de suas ideias parecem estar bloqueadas por estruturas autorreferenciais (circularidade, tautologia, regressão ao infinito, paradoxo) em suas versões específicas da teoria do discurso. Como o discurso racional pode ser justificado, se não pelo próprio discurso racional (Habermas)? Como essas formações discursivas que governam a epistème de toda

\footnotetext{
41 Para as ciências, cf. FOUCAULT, 1974, cap. 2, 3, 7; para o direito, cf. FOUCAULT, 1979.

42 FOUCAULT, 1974, cap. 9.

43 DREYFUS; RABINOW, 1982, p. 84.

44 Para uma crítica, cf. HONNETH, 1985, p. 168 et seq.; HABERMAS, 1987a, cap. 10.
} 
uma época histórica podem ser transformadas, senão pelas próprias formações discursivas (Foucault)?

Ambos os autores estão bem cientes de que essas questões necessariamente levam ao paradoxo, mas sua solução é evitar o paradoxo a qualquer custo. É claro que, no final, os paradoxos da autorreferência não podem ser evitados; eles simplesmente reaparecem ao fim dos desvios. Quando Habermas encontra o fundamento transcendental da comunicação na distinção entre a situação de fala ideal e as situações de fala reais, essa distinção é, em si mesma, empírica ou transcendental? Alternativamente, quando ele reintroduz o sujeito no discurso, os paradoxos clássicos do sujeito autorreflexivo estão obviamente fadados a reaparecer. Quando Foucault identifica os fundamentos do discurso em constelações de poder onipresentes, ele o faz sob pena de ver ressurgirem os paradoxos autorreferenciais de poder.

A teoria da autopoiese ${ }^{45}$ lida com esses paradoxos da autorreferência de uma maneira diferente: não evite paradoxos, mas faça bom uso deles! Se os discursos sociais são sistemas autopoiéticos, isto é, sistemas que recursivamente produzem seus próprios elementos a partir de uma rede de elementos, eles estão de fato fundados nessa autorreferencialidade que Habermas e Foucault tentam desesperadamente evitar ${ }^{46}$. Como sistemas autopoiéticos, os discursos precisam encontrar justificação em sua própria circularidade e não podem deixar de produzir "regularidades que se regulam” e governam a transformação de suas próprias regularidades. O paradoxo da autorreferência, então, não é uma falha que temos de evitar a todo custo na reconstrução intelectual do discurso, mas sua própria realidade, que não podemos evitar de forma alguma.

A aplicação recursiva das operações aos resultados dessas mesmas operações não leva necessariamente ao "paradoxo do bloqueio paradoxal” ou à pura arbitrariedade; sob certas condições, leva ao surgimento de “autovalores ${ }^{47}$ ”. Do contínuo e recursivo “computar do computar”, os discursos sociais “cegamente” apreendem os modos de operação válidos ao lidar com o ambiente ao qual eles não têm acesso direto ${ }^{48}$.

A consequência epistemológica é um construtivismo radical ${ }^{49}$. Qualquer cognição - seja ela psíquica ou social, seja científica, política, moral ou jurídica - é uma construção puramente interna do mundo exterior; a cognição não tem acesso à realidade "lá fora”. Qualquer atividade cognitiva -

45 LUHMANN, 1984; MATURANA; VARELA, 1980; FÖRSTER, 1981.

46 LUHMANN, 1986a, p. 172, 1986d, p. 129, 1988b, p. 153.

47 FÖRSTER, 1981, p. 274, 1985, p. 36.

48 Para uma elaboração dessas observações um tanto errôneas, cf. TEUBNER, 1989.

49 ARBIB; HESSE, 1986; FÖRSTER, 1981; GLASERSFELD, 1975, 1981, 1985; LUHMANN, 1984, p. 647; MATURANA; VARELA, 1980; PIAGET, 1971; ROTH, 1984, 1987; SCHMIDT, 1987. 
seja ela teórica ou empírica - nada mais é do que uma construção interna da unidade cognoscente; todo procedimento de teste que finge comparar a validade de construções internas à realidade externa é apenas uma comparação interna de diferentes construções do mundo.

Nessa versão radicalizada de “construção social da realidade”, não há lugar para a ação e o pensamento individuais ${ }^{50}$. A autopoiese social baseia-se exclusivamente na comunicação - definida como a síntese dos processos de enunciação, informação e entendimento - que reproduz recursivamente a própria comunicação ${ }^{51}$. A construção social da realidade e a construção psíquica da realidade são nitidamente separadas.

Aqui reside a importante diferença em relação a Habermas, que no ambíguo conceito de intersubjetividade mistura comunicação e consciência, e também em relação a Foucault, para quem o sujeito nada mais é do que uma construção historicamente contingente das constelações de discurso/ poder em mutação. Para a teoria da autopoiese, os processos psíquicos formam uma rede reprodutiva fechada - a autopoiese psíquica - acessível apenas a eles próprios e inacessível a qualquer processo comunicativo. A comunicação, por sua vez, forma uma rede autorreprodutiva fechada - a autopoiese social - acessível apenas à comunicação e inacessível a qualquer processo psíquico.

Certamente, os indivíduos humanos reaparecem nesse mundo da comunicação, mas apenas como construções comunicativas, como artefatos semânticos, sem correspondência com a consciência ou com os processos autopoiéticos no mundo psíquico ${ }^{52}$. Processos psíquicos e sociais de fato coexistem; eles são “acoplados” por sincronização e coevolução, mas não há sobreposição em suas operações. Não há nada além de uma simetria das construções de realidade: os processos psíquicos produzem construções mentais da sociedade, e os processos sociais produzem construções comunicativas da psique.

Nesses dois aspectos - radicalização do construtivismo e desindividualização do discurso Luhmann está expandindo aquilo que Habermas e Foucault desenvolveram em suas versões da epistemologia social. No entanto, há um terceiro aspecto na teoria da autopoiese de Luhmann que claramente vai além da análise do discurso em sua versão parisiense ou frankfurtiana - a visão da modernidade como um conflito irreconciliável de diferentes epistèmes ${ }^{53}$. Enquanto Foucault vê na história as rupturas nas formações do discurso que ditam uma epistème paradigmática, em toda a sociedade, para uma certa época histórica, e interpreta a época moderna como governada por uma

\footnotetext{
50 Para a relação entre observação individual e observação social, cf. LUHMANN, 1983, p. 1; 1985, p. 402, 1986b, p. 313.

51 LUHMANN, 1984, p. 193, 1986b, p. 172 et seq.

52 LUHMANN, 1984, p. 158, 1986b, p. 313.

53 LUHMANN, 1988a, p. 335 et seq.
} 
epistème "subjetivista” generalizada após a revolução kantiana ${ }^{54}$, Luhmann vê a modernidade como a fragmentação da sociedade em uma pluralidade de discursos autônomos: a multiplicação de epistèmes na sociedade. A característica crucial da sociedade moderna é a perda de um modo unificado de cognição.

A sociedade é vista como fragmentada em uma multiplicidade de redes comunicativas fechadas. Cada rede comunicativa constrói uma realidade própria que é, a princípio, incompatível com as construções de realidade das outras redes; ao mesmo tempo, há uma multiplicação e fragmentação de individualidades que corresponde à multiplicação e fragmentação de discursos sociais. Com base em seu código e programas específicos, cada rede comunicativa especializada produz "pessoas" - artefatos semânticos de atores individuais - aos quais as ações são atribuídas ${ }^{55}$. O "ser múltiplo"56 é produto da fragmentação dos discursos sociais na modernidade.

Essa fragmentação da sociedade em diferentes epistèmes é um dos pontos mais fortes da teoria de Luhmann - e, ao mesmo tempo, seu "ponto cego”. A ênfase dada à fragmentação, diferenciação, separação, fechamento e autorreferência nas epistèmes sociais cria problemas, para dizer o mínimo, pois sua interconexão, interferência, abertura e heterorreferência podem ser teoricamente reconstruídas ${ }^{57}$.

Ao contrário de Habermas e Foucault, que tentam evitar a qualquer custo as armadilhas da autorreferência, Luhmann enfrenta corajosamente realidades autorreferentes no direito e na sociedade, chegando a declarar que o direito se baseia em paradoxos de autorreferência ${ }^{58}$. No entanto, uma teoria que lida extensivamente com a autorreferência pode, em última instância, prender-se ao fechamento de construções autorreferenciais que ela própria criou; e o problema óbvio que a teoria da autopoiese tem de enfrentar é como lidar com as inter-relações de diferentes epistèmes autônomas, seus conflitos, suas incompatibilidades, suas interferências ${ }^{59}$.

As questões ainda em aberto para uma "teoria de epistèmes fragmentadas” são: Existe algo como um mínimo epistêmico, na sociedade moderna, que sirva como uma base comum para a autonomização dos discursos sociais? Alguém encontra covariação ou mesmo tendências coevolucionárias entre epistèmes sociais autônomas? Ou a única maneira de conectá-las é através da reconstrução de uma epistème dentro da estrutura de outra epistème?

\footnotetext{
4 FOUCAULT, 1974, cap. 9, 1979, cap. 4.

5 LUHMANN, 1984, p. 155 et seq.

ELSTER, 1986, ETZIONI, 1988.

57 Para uma crítica mais detalhada, cf. TEUBNER, 1990.

58 LUHMANN, 1988b.

59 Para os primeiros passos nessa direção, cf. LUHMANN, 1988a, 1990.
} 
Essas questões reaparecerão quando examinarmos em detalhes, com base na discussão precedente, a forma como uma epistemologia construtivista do direito reconstitui a cognição jurídica em seu conflito com outros modos de cognição na sociedade (ver seções VII e VIII, à frente).

\section{DIREITO - UM ASSUNTO EPISTÊMICO?}

Como o direito pensa? Mary Douglas, em um livro recente, levantou novamente a velha questão, em How Institutions Think (1986). Depois de um empolgante flerte com a "consciência coletiva” de Émile Durkheim e a "Denkkollektiv" de Ludwig Fleck, ela finalmente encontra seu caminho de volta ao bom e velho individualismo: claro, é o membro individual da instituição que pensa. No entanto, seu pensamento é influenciado pelo contexto institucional. Nessa versão da epistemologia social, o elemento social é representado pela socialização da mente individual. É isto. O coletivismo é proibido e o individualismo felizmente sobrevive após uma dose saudável de socialização.

Com nossa reconstrução seletiva de Habermas, Foucault e Luhmann na epistemologia social, porém, o quadro muda drasticamente. É verdade que a cognição individual é moldada por instituições sociais como o direito, através da socialização (e aqui o construtivismo acrescentaria que, como não há acesso da comunicação à consciência, a socialização só pode ser autossocialização). Mas isso é apenas metade da história. A outra metade é que instituições como o direito "pensam” independentemente da mente de seus membros.

O direito processa informações de maneira autônoma, cria mundos de significado, estabelece metas e propósitos, produz construções de realidade e define expectativas normativas - e tudo isso totalmente à parte das construções de mundo nas mentes dos advogados. Essa epistemologia legal construtivista é ao mesmo tempo não individualista e não coletivista: ela não necessita de atores e intenções individuais, nem pressupõe a existência de uma entidade coletiva supraindividual, “Denkkollektiv,” “conscience collective”, Mundo III, consciência jurídica ou Weltgeist.

Direito é comunicação e nada além de comunicação. Através dessa mesma conceitualização, é possível evitar as armadilhas do individualismo metodológico que define o direito como um “conjunto de regras que restringem a ação individual” e que, além da expressão genérica das consequências não intencionais, não tem nenhuma ferramenta com a qual analisar a autonomia do social, sem falar no "legal proprium ${ }^{60 "}$. Ao mesmo tempo, ela evita as armadilhas do coletivismo que

60 SELZNICK, 1968. 
vê o direito como um assunto supraindividual que não pode explicar quem está, de fato, agindo em nome do Weltgeist.

A construção precisa é a seguinte ${ }^{61}$. O direito é definido como um sistema social autopoiético, isto é, uma rede de operações elementares que reproduz recursivamente operações elementares. Os elementos básicos desse sistema são comunicados, não regras ou normas ${ }^{62}$; o direito não é, como nas teorias jurídicas analítico-normativistas, um sistema de normas. As definições sociológico-realistas do direito como um sistema de profissionais e instituições jurídicas também são problemáticas, porque veem os atores humanos como os elementos básicos do direito e de outras instituições sociais. O caráter autorreprodutivo do direito como um processo social torna-se inteligível somente quando se elegem os comunicados como elementos básicos do direito.

O direito como sistema social autopoiético não é composto de normas nem de tomadores de decisões jurídicas, mas de comunicados jurídicos, definidos como a síntese de três seleções de significado: enunciação, informação e compreensão. Esses comunicados estão inter-relacionados entre si em uma rede de comunicados que não produz nada além de comunicados. Isso é o que basicamente se entende por autopoiese: a autorreprodução de uma rede de operações comunicativas pela aplicação recursiva de comunicados aos resultados de comunicações anteriores. O direito como uma rede comunicativa produz comunicados jurídicos.

Os comunicados jurídicos são os instrumentos cognitivos pelos quais o direito, como discurso social, é capaz de “ver” o mundo. Os comunicados jurídicos não podem alcançar o mundo exterior real: nem a natureza nem a sociedade. Eles só podem se comunicar sobre a natureza e sobre a sociedade. Qualquer metáfora sobre seu acesso ao mundo real é equivocada. Eles não recebem informações do mundo exterior que "filtrariam e converteriam" de acordo com as necessidades do processo jurídico; o direito não é instruído pelo mundo exterior. Existe apenas a construção do mundo exterior pelo direito. Isso não quer dizer que o direito “inventa” arbitrariamente a realidade social; uma perspectiva construtivista não deve ser confundida com “solipsismo metodológico ${ }^{63}$ ”; em vez disso, procura um “caminho do meio” entre o representacionalismo e o solipsismo ${ }^{64}$.

O construtivismo jurídico, então, pressupõe a “existência” de um meio para o direito. O objetivo não é um isolamento monadológico do direito, mas a construção autônoma de modelos

61 Para uma discussão elaborada das características da lei autopoiética, ver TEUBNER, 1988b, 1988c, 1990.

62 No original, “rules”. Acostumamo-nos, no Brasil, a diferenciar, no contexto jurídico, regra e norma, porém, no contexto da definição do direito como sistema autopoiético a que se refere Teubner, essa distinção não é relevante [N. do T.].

63 FODOR, 1980.

64 VARELA, 1984, p. 217. 
jurídicos da realidade sob a impressão de perturbações do meio. Ordem jurídica, a partir do ruído social!

E quanto às percepções de mundo de advogados e leigos? Não é a agregação deles que forma a visão de mundo coletiva do direito ${ }^{65}$ ? É claro que o processo comunicativo do direito precisa de advogados e leigos; não funcionaria sem suas intenções, estratégias e ações. Mas suas intenções (subjetivas, internas, psíquicas) nunca entram na comunicação (objetiva, externa, social) do direito. Eles só integram parte dos processos psíquicos, acompanhando o processo social do direito e coevoluindo com ele. O direito como processo comunicativo não é acessível a nenhum dos processos psíquicos que acompanham advogados e leigos e, vice-versa, não tem acesso a eles. Eles funcionam apenas como "perturbações", como “chocs exogènes ${ }^{66 "}$ sob cuja pressão o processo comunicativo do direito constrói sua própria ordem autônoma e cria o mundo do significado jurídico ${ }^{67}$.

Mas o direito como um processo social não lida constantemente com pessoas reais? O direito não é movido por motivos reais, estratégias, ações de clientes, profissionais, juízes e legisladores? O direito não se refere constantemente a estados mentais de pessoas reais, às suas intenções, objetivos, consentimento, dissidência, erros, negligência, mens rea ${ }^{68}$ ? Obviamente, o direito faz isso. Mas as “pessoas” com quem o direito como processo social lida não são pessoas reais de carne e osso, não são seres humanos com cérebro e mente, não são os sistemas psíquicos autopoiéticos acima mencionados. São meros construtos, artefatos semânticos produzidos pelo próprio discurso jurídico. Estados mentais são "na realidade construtos de discursos práticos, necessários para a formação de círculos comunicativos, de comunidades discursivas ${ }^{69 "}$.

Como construtos sociais, são indispensáveis à comunicação jurídica, pois o direito como processo social precisa atribuir a comunicação a certos atores (individuais ou coletivos) para continuar sua autorreprodução. Esses “atores”, no entanto, são apenas feixes de papéis, máscaras de personagens, produtos internos de comunicação jurídica ${ }^{70}$.

O mundo, densamente povoado, das pessoas jurídicas - os queixosos e réus, os juízes e legisladores, as partes de um contrato, as corporações e o Estado - é uma invenção interna do processo jurídico. Não apenas a empresa: qualquer pessoa de direito, coletiva ou individual, física ou jurídica,

65 Cf. as objeções baseadas no ator contra um direito autopoiético, em FEBBRAJO, 1985, p. 134 et seq.; KERCHOVE; OST, 1988, p. 157 et seq.; OST, 1988, p. 87 et seq.

66 KERCHOVE; OST, 1988, p. 159.

67 Cf. FÖRSTER, 1981; TEUBNER, 1990.

68 Categoria jurídica frequentemente utilizada na common law, similar ao tipo subjetivo, ainda que com ele não se confunda [N. do T.].

69 PIZZORNO, 1989, p. 9.

70 Para uma elaboração sobre atores coletivos, cf. TEUBNER, 1988a, p. 133 et seq.; 1988c, p. 66 et seq. 
é apenas aquele "ser artificial, invisível, intangível, existindo apenas na contemplação do direito" descoberto pelo Juiz Chefe Marshall no famoso caso de Dartmouth College v. Woodward ${ }^{71}$.

Assim, os atores humanos têm uma "identidade dupla” no mundo da autopoiese. Enquanto em sua existência social eles são construções pálidas de sistemas sociais autopoiéticos (entre eles o direito), em sua existência psíquica eles próprios são sistemas autopoiéticos vibrantes. É claramente errado argumentar, como fazem alguns críticos, que a autopoiese desumaniza a sociedade ${ }^{72}$, não tem lugar para atores e intenções ${ }^{73}$, não leva em conta o indivíduo como sujeito epistêmico ${ }^{74}$, e representa uma “desumanização total do direito ${ }^{75}$ ”. O ponto não é o definhar do sujeito individual, mas a multiplicação de centros de cognição. Os discursos sociais são os novos sujeitos epistêmicos que competem com a consciência do indivíduo.

Na medida em que a autopoiese insiste na autonomia epistêmica de uma multiplicidade de discursos sociais, ela toma parte na "descentralização do sujeito”, isto é, afasta o sujeito de sua posição privilegiada como o único e último centro de conhecimento. Se falamos de atores humanos na lei, temos de distinguir cuidadosamente entre a reprodução autopoiética da consciência humana isto é, a realidade operativa dos processos psíquicos - e a reprodução autopoiética da vida social do direito na qual os atores humanos são não elementos, mas realidades sociais construídas.

\section{A ARMADILHA EPISTÊMICA}

Enquanto a análise do discurso na tradição de Foucault vê a época moderna nas garras de uma epistème pervasiva ${ }^{76}$ e vê o direito, como outras disciplinas, apenas como uma expressão particular do complexo poder/conhecimento ${ }^{77}$, a teoria da autopoiese vê a sociedade moderna como fragmentada em múltiplas epistèmes autônomas ${ }^{78}$. A autopoiese transforma o discurso jurídico moderno em um conflito irreconciliável entre autonomia e heteronomia epistêmica ${ }^{79}$. A dinâmica da diferenciação social força o discurso jurídico a produzir suas próprias construções de realidade, mas

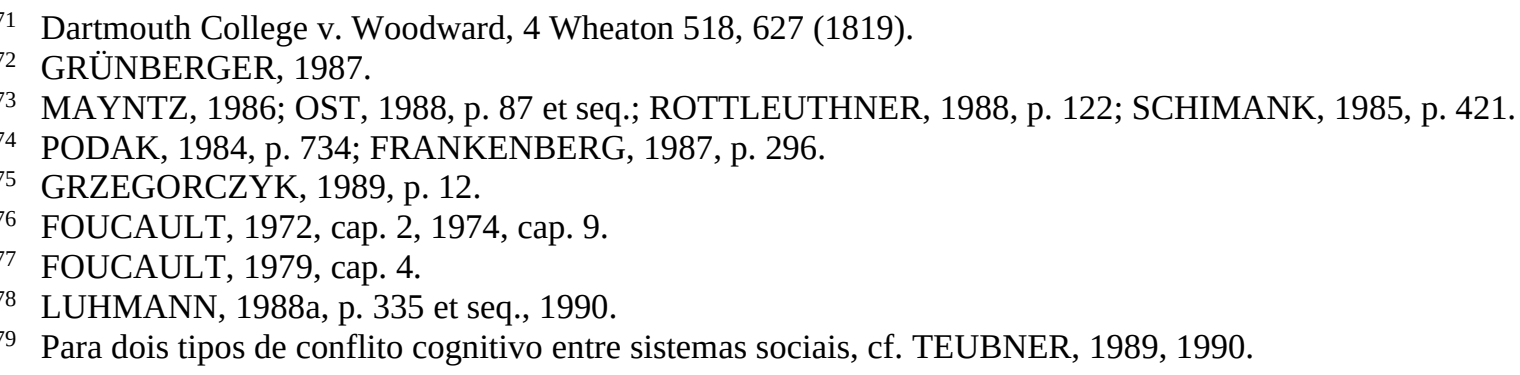


a mesmíssima dinâmica torna o direito dependente de uma multiplicidade de epistèmes autônomas em conflito.

A autonomia epistêmica do direito resulta da fragmentação da sociedade moderna que conduz o direito à autopoiese de segunda ordem ${ }^{80}$. Na dinâmica da evolução social, as relações autorreferenciais se multiplicam dentro do processo jurídico, culminando em um vínculo hipercíclico entre os componentes do direito. O direito se torna autônomo em relação à comunicação social geral. Ele se desenvolve em uma rede comunicativa fechada que produz não apenas atos jurídicos como seus elementos e regras jurídicas como suas estruturas, mas também construções jurídicas de realidade. A autonomia do direito moderno se refere primariamente às suas operações normativas que se tornam independentes da normatividade moral e política ${ }^{81}$; e, secundariamente, autonomia referese às operações cognitivas do direito que - sob a pressão de operações normativas - constroem imagens idiossincráticas da realidade e afastam-nas das construções de mundo da vida cotidiana e daquelas do discurso científico ${ }^{82}$.

Nesse contexto, Baudrillard ${ }^{83}$ fala de "hiper-realidade" como um afastamento de "teorias dependentes da realidade” em direção a “realidades dependentes da teoria”. Numa reformulação autopoiética, este processo seria descrito como uma autonomização de discursos sociais especializados na qual as construções de realidade da comunicação social geral são cada vez mais substituídas por construções de realidade dos discursos especializados. O discurso jurídico inventa e trata de uma "hiper-realidade" jurídica que perdeu contato com as realidades da vida cotidiana e, ao mesmo tempo, sobrepõe novas realidades à vida cotidiana. É uma “efficacité quasi magique”, como chama Bourdieu, que a lei possui em suas práticas de “criação de mundo ${ }^{84 ” . ~ G r z e g o r c z y k ~}{ }^{85}$ fala da lei como uma "hermeneutique officielle $d u$ monde" que organiza o mundo social. "Fatos institucionais”, como a personalidade jurídica, o contrato, a vontade, são apenas uma pequena parcela dos construtos da realidade jurídica, flutuando em um oceano de "fatos brutos” da comunicação social difusa. O discurso jurídico modifica cada vez mais o significado das visões cotidianas de mundo e, em caso de conflito, as substitui por construtos jurídicos.

De uma perspectiva construtivista, nem as próprias realidades sociais, nem o senso comum, nem a observação cientificamente controlada é capaz de contestar a autoridade epistêmica do direito.

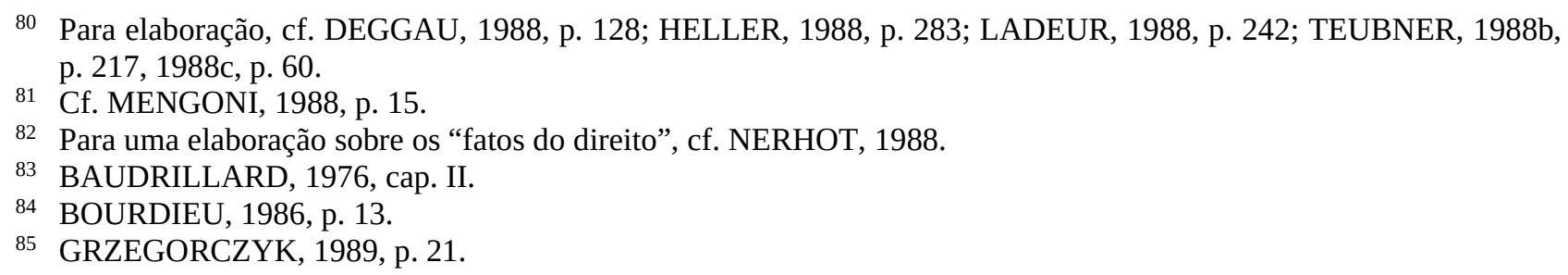


Uma epistemologia social de base construtivista pode explicar por que o direito parece ser um “discurso essencialmente autovalidador”, que se deve esperar que seja “impermeável ao sério desafio de outros campos do conhecimento ${ }^{86 ”}$. É simplesmente ingênuo invocar a própria “realidade” social

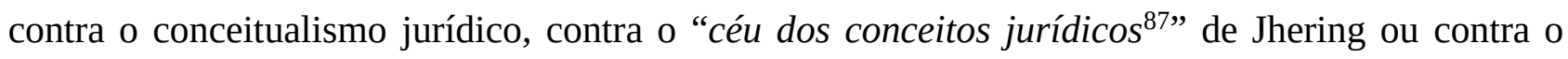
“absurdo transcendental” do direito ${ }^{88}$ de Cohen. Não há, diretamente, acesso cognitivo à realidade; existem apenas discursos concorrentes com diferentes construções de realidade. E tudo o que Jhering e Cohen têm a oferecer é seu próprio absurdo transcendental em um paraíso diferente de conceitos jurídicos. Há alguma razão para acreditar que o Freirecht, a jurisprudência sociológica ou o realismo jurídico tenham tornado o discurso jurídico mais realista? De jeito nenhum. Eles não aproximaram os conceitos jurídicos da realidade social “lá fora”. Eles apenas substituíram uma jurisprudência conceitual por outra jurisprudência conceitual. "Interesses sociais”, os átomos da jurisprudência realista, são ficções irreais, produtos semânticos artificiais, assim como os "sujeitos jurídicos”, os átomos da jurisprudência clássica.

"Direito e sociedade” e “direito e economia” não vão fazer bem algum se pretenderem invocar a autoridade da observação científica controlada contra as “mistificações do mundo real” dos advogados $^{89}$. O que o construtivismo epistemológico faz é desconstruir as alegações da ciência moderna de ter acesso privilegiado à realidade ${ }^{90}$. A ciência não descobre fatos externos; a ciência produz fatos. "A ciência é, literalmente, construtora de novos fatos ${ }^{91 ”}$. O construtivismo radical sustenta que "a ciência produz uma construção de mundo que é validada por seus próprios mecanismos, e não pelo mundo como tal. Assim, a ciência não pode reivindicar autoridade para descobrir e comunicar a outros o único e correto meio de acesso ao mundo real ${ }^{92}$ ". Se podemos acreditar em reconstruções construtivistas do processo científico, então o célebre experimento controlado não é o que ele pretende ser - um teste de uma teoria interna contra a realidade externa -, mas um mero teste de coerência interna que compara dois construtos produzidos de acordo com diferentes requisitos procedimentais: a lógica do raciocínio teórico e a lógica do laboratório.

Tomemos um exemplo. A teorização das ciências sociais sobre a relação entre organização e ação coletiva não é de modo algum superior à doutrina jurídica sobre a relação entre a empresa e a

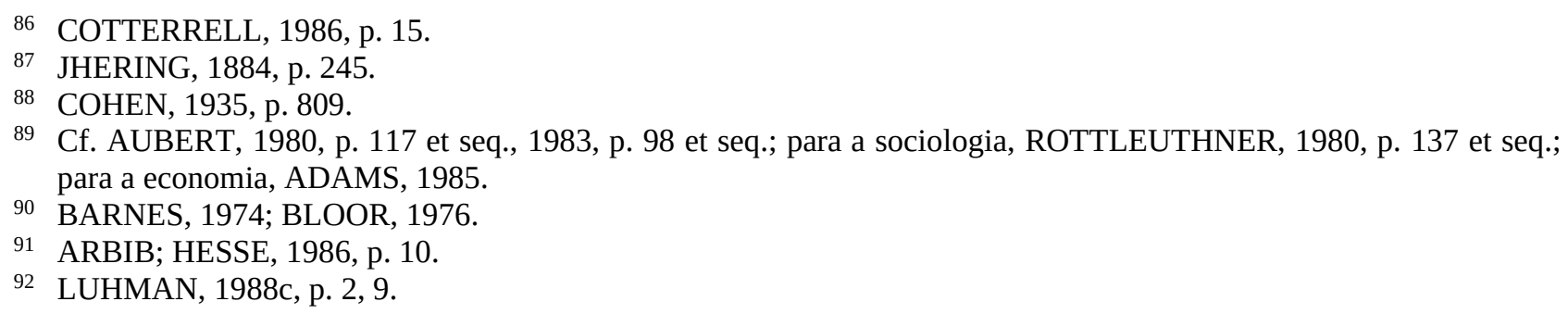


personalidade jurídica; ambas são artefatos discursivos cuja construção não é arbitrária, mas guiada racionalmente por códigos e programas específicos. Da mesma forma, fatos empíricos sobre disfunções na vida organizacional - fatos concretos que resultam de investigações cientificamente controladas - não são de modo algum mais “verdadeiros” do que fatos jurídicos sobre a violação de deveres corporativos que são produzidos sob a orientação firme das regras da teoria da prova. Em ambos os casos, procedimentos e convenções racionais da investigação factual levam a afirmações empíricas sobre a realidade. Eles servem como evidência "rígida", confirmando ou refutando alegações "brandas ${ }^{93 ”}$ baseadas em especulações teóricas ou no raciocínio jurídico. Se esses fatos empíricos conflitam entre si - o que não é tão raro -, então não há superioridade dos construtos científicos sobre as construções jurídicas, como alguns sociólogos gostariam ${ }^{94}$. A autoridade epistêmica é reivindicada tanto pelo discurso científico quanto pelo discurso jurídico - e com razão. O que um realismo ingênuo chamaria de observação de “fatos” é, em ambos os casos, a produção de artefatos cuja verdade é garantida por procedimentos formalizados de investigação factual, procedimentos que diferem consideravelmente em direito e ciência. Esses procedimentos, por sua vez, são convenções, não arbitrárias, mas seleções estruturais que refletem as escolhas feitas na história do discurso científico e jurídico ${ }^{95}$.

A autoridade epistêmica do discurso jurídico é inegável na modernidade. Assim, encontramos maneiras e meios de lidar com fatos de múltiplas verdades - verdade científica, verdade jurídica, verdade política. A coisa julgada é o exemplo clássico de um conflito institucionalizado entre fatos legais e fatos científicos. Mesmo que se possa provar com evidências científicas que uma declaração de fato em um procedimento jurídico é flagrantemente falsa, essa declaração de fato do tribunal - e ainda pior, suas consequências jurídicas, econômicas e sociais - não será revertida (apartando-se exceções estritamente definidas), a menos que os requisitos processuais sejam cumpridos e os procedimentos de apelação esgotados. Obviamente, fatos científicos colidem com fatos jurídicos, mas estamos acostumados a conviver com essa colisão, racionalizando-a e invocando para tal “altos valores”, como a segurança jurídica, ou então apelando para o relativismo de nossas diferentes províncias culturais.

93 No original, “hard” e "soft” [N. do T.]

94 OPP, 1973.

95 Assim, o relativismo resultante de diferentes discursos sociais não é um relativismo “vale tudo”. É um relativismo que convida a "elevar o status das outras 'mitologias' por meio de uma investigação mais cuidadosa de suas credenciais metodológicas e cognitivas” e a examinar "os vários tipos de critérios de aceitabilidade que se aplicam a diferentes tipos de modelos e mitos construídos” (ARBIB; HESSE, 1986, p. 10). 
No entanto, as coisas não são tão fáceis. O notório “jurist als solcher” de Windscheid, que tem direito pela lei da diferenciação social a não "se preocupar com considerações éticas, políticas ou econômicas ${ }^{96 ”}$, é forçado pela mesma lei a renunciar ao direito puro e a incorporar essas considerações não jurídicas em seu raciocínio autônomo. Isso é o que eu chamaria de "armadilha epistêmica” do direito moderno. O direito é forçado a produzir uma realidade jurídica autônoma e não pode, ao mesmo tempo, imunizar-se contra realidades conflitantes produzidas por outros discursos da sociedade.

A razão subjacente dessa confusão é “interferência”, isto é, a difusão mútua do direito e de outros discursos sociais ${ }^{97}$. Esse é um dos problemas mais desafiadores para a autopoiética se essa teoria pretende evitar as falácias do solipsismo e do monadismo ${ }^{98}$. Embora o discurso jurídico seja fechado em sua autorreprodução e produza suas próprias construções da realidade, ele permanece sendo comunicação social, utiliza as construções sociais gerais da realidade e influencia a comunicação social geral por suas construções de mundo. Todo ato jurídico é, ao mesmo tempo, uno $a c t u$ - um evento de comunicação social geral. O mesmíssimo evento comunicativo, portanto, está ligado a dois discursos sociais, o discurso institucionalizado especializado do direito e a comunicação social difusa e geral. A interferência do direito e de outros discursos sociais não significa que eles se fundem em um superdiscurso multidimensional, nem que a informação seja "trocada” entre eles. Em vez disso, a informação é constituída novamente em cada discurso e a interferência não acrescenta nada além da simultaneidade de dois eventos comunicativos ${ }^{99}$. Assim, os construtos jurídicos são expostos aos construtos de outros discursos da sociedade, particularmente aos construtos da ciência. Eles são expostos a um teste de "coerência social” que substitui a antiga ficção de um teste de correspondência à realidade externa.

No mundo da comunicação não jurídica, as construções do direito são inevitavelmente vencidas nessa competição epistêmica. Aqui, a ciência tem a vantagem de se especializar em procedimentos para operações puramente cognitivas, enquanto o direito usa operações cognitivas apenas secundariamente, moldando assim seus procedimentos cognitivos num contexto institucional diferente. Mas e o mundo da comunicação jurídica em tribunais, escritórios de advocacia e câmaras legislativas? Aqui, o discurso jurídico alega ter o direito de “escravizar” operações cognitivas de acordo com o contexto normativo e o objetivo institucional. Os modelos “empíricos” de comunicação

\footnotetext{
WINDSCHEID, 1904, p. 101.

Cf. MENGONI, 1988, p. 23.

98 Cf. seção V. supra.

99 Para detalhes, consulte TEUBNER, 1989, 1990.
} 
jurídica estão firmemente presos a modelos “estratégicos” e “operacionais"100”. No entanto, é o contexto institucional do próprio processo jurídico que produz uma contradição interna. Embora exija construções idiossincráticas da realidade por meio da comunicação jurídica, esse contexto institucional força a comunicação jurídica a reconstruir as construções científicas da realidade e a expor - mesmo dentro do império do direito - construções jurídicas da autoridade "superior” da ciência em questões cognitivas.

O caráter conflituoso dos procedimentos legais - litígios, legislatura e disputas acadêmicas - força o discurso jurídico a examinar qualquer conhecimento novo produzido fora do mundo jurídico, se for "relevante” para o direito. Qualquer advogado que não contestasse a validade de provas à luz de um novo método de pesquisa científica agiria contra seus interesses e violaria seus deveres profissionais.

No processo legislativo, os oponentes políticos, digamos, da legislação em saúde, certamente contestarão as medidas da lei se houver evidências científicas da inexistência de um nexo pressuposto entre uma doença e certos fatores causais. Além disso, acadêmicos de direito e economia acessam os maiores prêmios de reputação quando informam os tribunais sobre seus ingênuos modelos précientíficos de comportamento humano e propõem alternativas cientificamente comprovadas.

A armadilha epistêmica do direito moderno, portanto, produz um desafio de primeira ordem à doutrina jurídica, à teoria jurídica e à sociologia jurídica. Implacavelmente, a doutrina jurídica pela boca de juízes e professores de direito - apresenta propostas positivas sobre como escapar da armadilha. Reflexivamente, a teoria jurídica ajuda a ampliar as rotas de fuga, generalizando soluções particulares e importando conhecimento de outras disciplinas. A sociologia jurídica positiva, por vez, estuda zelosamente as correlações entre essas semânticas legais e o contexto sociocultural mais amplo, enquanto continua sendo o privilégio de estudos sociojurídicos críticos “destruir” essas tentativas, demonstrando aos juristas, em uma análise desconstrutiva e implacável, que eles ainda estão na antiga armadilha.

\section{ROTAS DE FUGA}

Renunciar à autoridade epistêmica, pelo menos parcialmente, seria a maneira mais fácil de escapar desses problemas. De fato, Luhmann, que provavelmente subestima a possibilidade de conflito de autoridade entre as epistèmes sociais, parece favorecer essa rota de fuga quando afirma

100 Para uma elaboração das restrições mútuas exercidas entre os diferentes modelos internos do mundo exterior, ver TEUBNER, 1982, p. 96 et seq. 
ser dispensável que o direito reexamine interpretações cotidianas e construções científicas, como “mulher”, “capacidade volumétrica”, “habitante”, “tálio.” “Se questões como 'mulheres existem?’, etc. realmente surgirem, elas podem ser dispensadas ou deixadas para a filosofia ${ }^{101}$ ”. Infelizmente, essa separação limpa de espaços sociais não existe. Além disso, com essa divisão de trabalho entre os discursos sociais, não se exploraria a riqueza do conceito de autopoiese e contraevidências empíricas teriam que ser enfrentadas.

Na prática cotidiana da tomada de decisões jurídicas, o direito é constantemente forçado a decidir autonomamente sobre questões cognitivas que estariam dentro da competência da investigação científica ou do senso comum. O direito sempre pode iniciar suas operações pressupondo entendimento do senso comum e referindo-se à ciência; no entanto, sempre que, no processo, essas declarações cognitivas se tornam controversas - e geralmente é o caso de questões política e juridicamente “quentes” - o direito não pode mais desviar-se delas ou deixá-las para a filosofia. Então, hic et nunc, o processo legal deve garantir procedimentos para resolver essas divergências e tomar decisões baseadas na determinação normativa dessas questões, mesmo que sejam controversas ou cientificamente indetermináveis.

Mais particularmente, conflitos políticos e jurídicos na área de direito ambiental, que exigem muita experiência científica e técnica extrajurídica, mostram até que ponto as decisões jurídicas devem se basear em uma avaliação jurídica específica de controvérsias científicas - ou então serem tomadas sem a orientação de resultados científicos ${ }^{102}$.

A outra principal rota de fuga da armadilha epistêmica do direito é a integração do direito e das ciências sociais. Em vez de separar claramente os domínios da cognição jurídica dos da cognição científica, supõe-se que o discurso jurídico incorpore o conhecimento social em suas construções de mundo e revise permanentemente os modelos jurídicos da realidade social de acordo com o acúmulo de conhecimento nas ciências sociais. Desde os tempos de Jhering, Geny e Pound, até as variações mais recentes dos movimentos “direito e...”, essa foi a aventura intelectual mais desafiadora do pensamento jurídico moderno.

O que a epistemologia jurídica pode aprender com quase cem anos de experimentação com “direito e sociologia”? Embora o pensamento das ciências sociais tenha sido notavelmente bemsucedido em influenciar a prática jurídica ${ }^{103}$, as grandes expectativas de esclarecimento jurídico surgidas na academia foram frustradas nos tribunais. Psiquiatria, sociologia, análise de políticas e

\footnotetext{
101 LUHMANN, 1988a, p. 340.

102 Cf., para a situação alemã, KITSCHELT, 1984; WINTER, 1987; WOLF, 1986.

103 Cf., por exemplo, COTTERRELL, 1984, p. 253 et seq.
} 
análise econômica entraram com sucesso na esfera jurídica, mas o resultado não é um maior grau de isomorfia da lei e conexão com a realidade social para resultar em padrões de decisões jurídicas mais racionais. Em vez disso, o esclarecimento das ciências sociais sobre o direito resultou em consequências imprevistas - a produção de artefatos híbridos com status epistêmico ambíguo e consequências sociais desconhecidas.

“Análise de interesse”, por exemplo, é um sucesso surpreendente dos esforços da “jurisprudência sociológica” para substituir o raciocínio jurídico formalista e conceitualmente derivado ${ }^{104}$. Hoje, a análise de interesse praticamente domina a tomada de decisões jurídicas nos tribunais: os tribunais analisam conflitos em termos de interesses sociais conflitantes subjacentes e os “equilibram” entre si de acordo com os padrões que eles inferem de objetivos legislativos expressos em um contexto comparável.

Mas o que é sociológico nesse tipo de jurisprudência sociológica? Nenhum sociólogo no mundo ousaria seguir advogados em suas tentativas de conceituar, operacionalizar e identificar empiricamente aqueles fenômenos chamados “interesses sociais” que figuram com destaque nas decisões jurídicas (por exemplo, as preocupações jurídicas de credores, devedores, vizinhos, corporações, regiões, estados), sem falar nos métodos jurídicos de “equilibrá-los”. Existem muitas premissas normativas explícitas e implícitas, baseadas em uma complexa rede de considerações doutrinárias e legislativas, que entram na análise de interesse jurídica. A análise do interesse jurídico, portanto, não pode ser legitimada do ponto de vista de teorias ou métodos sociológicos. Na prática, a análise de interesse é uma nova jurisprudência dos conceitos que foi originalmente subsidiada por construções das ciências sociais, mas que vem ganhando autonomia há muito tempo. Pode muito bem ser que a análise de interesse contenha elementos de uma nova racionalidade jurídica ${ }^{105}$, mas eles certamente são diferentes dos objetivos originais da jurisprudência sociológica, e evoluem por experimentação institucional, não pela incorporação do conhecimento sociológico.

A “análise de políticas ${ }^{106 ”}$ conta uma história semelhante. Basicamente, é um método de tomada de decisão inspirado no uso instrumental do conhecimento das ciências sociais ${ }^{107}$. Definir as metas consentidas no processo político, determinar as condições de fato da situação regulatória, escolher entre os instrumentos regulatórios de acordo com o conhecimento nomológico sobre relações

\footnotetext{
${ }^{104}$ Para uma análise recente da prática alemã e francesa no direito administrativo e sua interpretação sofisticada, cf. LADEUR, 1984, p. 11, 57.

105 Em termos de flexibilidade, abertura e capacidade de aprendizado, ver LADEUR, 1984, p. 216 et seq.

106 No original, “policy”, não politics [N. do T.]

107 Para uma declaração recente, ver ALBERT, 1986, p. 34 et seq.
} 
teleológicas, levar em consideração os efeitos colaterais e, se possível, aprender com a prática sobre consequências imprevisíveis e efeitos perversos!

Mas o que a prática jurídica fez dessa “jurisprudência racional”? Os operadores do direito simplesmente alteraram a descrição de seus métodos escolásticos de raciocínio doutrinário do nível de regras para o nível de "políticas”, programas, propósitos, objetivos e princípios que suplantam a análise das ciências sociais pela obscura hermenêutica da interpretação "teleológica”. O consequencialismo jurídico tornou-se, na prática, uma caricatura de uma análise causal cientificamente controlada, apoiada em evidências empíricas ${ }^{108}$. O que conta como consequência relevante de uma regra ou decisão jurídica derivada da doutrina jurídica é, de forma redundante, definido pela própria doutrina jurídica. Assim, a doutrina que originalmente deveria ser controlada por suas consequências sociais, agora controla suas consequências sociais.

Além disso, o cálculo racional das prováveis consequências da tomada de decisões acaba sendo na prática apenas a projeção do senso comum dos juízes. E o consequencialismo é levado a sério apenas no nível das regras, e não no nível das decisões individuais que, na prática, nunca são revertidas se o cálculo das consequências se mostrar errado. Novamente, somos confrontados não com a ciência social dentro do direito, mas com um novo tipo de doutrina jurídica que lida com “políticas” como os novos artefatos legais que substituem os antiquados “direitos e deveres”.

Pode-se continuar, analisando a “pobreza da psiquiatria”. É concebível, do ponto de vista de uma ciência positivista, que um especialista em psiquiatria dê uma opinião de como distinguir, abstratamente e/ou concretamente, entre imprudência, negligência ${ }^{109}$ e imperícia ${ }^{110}$ ? Embora, do ponto de vista científico, qualquer noção de culpa individual não seja senão uma "questão transcientífica” - questões que não podem ser respondidas pela ciência ${ }^{111}$ _, os psiquiatras forenses costumam dar tais opiniões, porque eles permitem que o direito "escravize” os conceitos básicos de sua disciplina.

A “análise econômica do direito” é um campo de batalha mais recente para a competição epistêmica. Ainda não se sabe se o imperialismo econômico prevalecerá ou se o dogma jurídico colonizará o pensamento econômico. Especialmente nas mãos dos advogados economicistas, os

\footnotetext{
108 Na Alemanha, cf. o animado debate sobre Folgenkontrolle, in LUHMANN, 1974; LÜBBE-WOLFF, 1981.

${ }^{109}$ No original, “guilt” e “negligence”. Não há correspondência de conceitos entre a common law e a civil law, mas o exemplo que o autor busca poderia ser igualmente encontrado em outros conceitos da subjetividade jurídica, como a distinção entre dolo eventual e culpa consciente [N. do T.].

110 Cf., por exemplo, PRINS, 1980, cap. 2.

111 Cf. MAJONE, 1979, 1989, p. 3 et seq.; WEINBERG, 1972.
} 
conceitos analíticos da economia passam por uma mudança sutil (e muitas vezes não tão sutil) em construções normativas que servem como pedras angulares para edifícios doutrinais jurídicos.

Se, por exemplo, examinarmos a nova literatura de economia jurídica que apresenta a empresa como um nexo de $\operatorname{contratos}^{112}$, nada resta dos princípios metodológicos da economia, formulados por Williamson em 1987: abertura teórica, prontidão para aprender com outros campos da experiência, refutabilidade de implicações e exposição à falsificação empírica. “Corporations as Contracts” (1988), do juiz Easterbook, é um protótipo de ortodoxia ideológica, rigidez doutrinária e imunização conceitual contra experiências contraditórias.

Essas observações polêmicas não devem ser mal-interpretadas. Elas não pretendem defender a pureza da conceituação acadêmica contra o uso estratégico/indevido de advogados com segundas intenções. Pelo contrário, pretendem demonstrar que as construções das ciências sociais não são apenas transformadas ou distorcidas, mas constituídas de novo, se incorporadas ao discurso jurídico. Elas não são importadas para dentro do direito com o rótulo “made in science”, mas são reconstruídas dentro da rede operacional fechada de comunicações jurídicas que lhes confere um significado bastante diferente do das ciências sociais ${ }^{113}$.

Não é uma questão de "mesma coisa vista sob diferentes ângulos, apropriadamente para diferentes interesses disciplinares, métodos, etc. ${ }^{114}$ ". Para tal seria necessário pressupor uma realidade subjacente capaz de unificar os diversos aspectos enfatizados em diferentes disciplinas e decidir entre descrições conflitantes. Em vez disso, as diferenças podem ser encontradas nas próprias realidades, produzidas por diferentes discursos, e são impossíveis de unificar ou reconciliar. Assim, a incorporação do conhecimento das ciências sociais não é realmente uma fuga do que chamamos de armadilha epistêmica do direito moderno.

Isso não resolve o conflito entre realidades jurídicas e científicas, mas acrescenta uma nova realidade que não é uma construção puramente jurídica nem uma construção puramente científica. Os construtos da jurisprudência sociológica, economia jurídica, “politologia jurídica” e similares são criaturas híbridas, produzidas no processo jurídico com autoridade emprestada das ciências sociais. Contudo, a autoridade e a responsabilidade epistêmicas não estão mais nas ciências sociais, mas no direito. E sua “verdade”, sua adequação social, sua viabilidade serão decididas não mais no processo de investigação científica, mas no processo de comunicação jurídico-normativa. Por exemplo, certas

\footnotetext{
112 Por exemplo, ALCHIAN; DEMSETZ, 1972; CLARK, 1985; FAMA; JENSEN, 1983; ROOS, 1988; SCHANZE, 1986, 1987.

113 "Muitas coisas dependem de perceber que a autonomia do direito não reside em sua liberdade de ser influenciado por causas e influências externas, mas na maneira pela qual ele as incorpora e responde a elas” (NELKEN, 1987).

114 AUBERT, 1980, p. 117 et seq., 1983, p. 98 et seq.; ROTTLEUTHNER, 1980, p. 137 et seq.
} 
construções psicanalíticas, bem como modelos totalmente determinísticos em psicologia, nunca serão construções viáveis em um mundo jurídico que se baseia em pressupostos de culpabilidade e responsabilidade individuais.

Em outro campo, o relativo sucesso da economia jurídica em comparação com a jurisprudência sociológica provavelmente não tem nada a ver com os valores “científicos” intrínsecos dos modelos envolvidos, mas com sua afinidade estrutural à doutrina jurídica tradicional. Se os tribunais que consideram questões de, digamos, negligência, políticas públicas, justiça e faculdades do “homem razoável” começam a recorrer a “normas sociais”, uma conceituação sociológica exigiria tempo, energia e dinheiro para pesquisas empíricas estendidas, enquanto uma conceitualização econômica, em termos de custos, requer uma cadeira.

Seria errado, no entanto, ver a incorporação do conhecimento social como “irracional”. Dada a tensão inerente entre as realidades científicas e jurídicas e a autoridade das ciências modernas, parece bastante racional para o direito tentar tornar as construções da realidade jurídica pelo menos compatíveis com os desenvolvimentos recentes nas ciências. A esse respeito, o direito se assemelha à religião ${ }^{115}$. Tanto no dogma do direito quanto no dogma teológico, é aconselhável manter o mundo da fé compatível com o mundo da verdade científica. No entanto, há mais na integração do direito e das ciências sociais do que apenas tornar compatíveis as construções contraditórias de mundo. O movimento “direito e...”, deve-se admitir, tem efeitos benignos para a qualidade da tomada de decisões do direito moderno em termos de justiça e utilidade. Os resultados mais recentes das ciências sociais e o desafio permanente que elas representam podem servir como um "conjunto de oportunidades” para a inovação jurídica. É uma fonte tremendamente rica para uma reconstrução contínua do mundo jurídico, comparável apenas à riqueza no que as pessoas consideram litigável. No entanto, o que acontece com esses construtos, uma vez que entram no cenário jurídico, não está mais nas mãos das ciências sociais. A seleção e retenção dessas variações é trabalho da evolução do direito.

Já há indícios de que essa reconstrução jurídica do conhecimento científico, se levada longe demais, torna-se arriscada. Na área de direito ambiental, por exemplo, Gerd Winter (1987) percebeu um aumento na “ansiedade dos juízes” em relação à avaliação técnica de riscos e outras incorporações jurídicas de descobertas científicas, juntamente com uma tendência a reduzir o escopo de questões juridicamente relevantes. Parece um retorno à primeira rota de fuga mencionada na oscilação permanente entre autonomia epistêmica e heteronomia. No entanto, existem outras tentativas de lidar com essa situação, incluindo experimentos com uma terceira solução, uma espécie de caminho

115 Para uma descrição construtivista do conflito entre ciência e religião, ver ARBIB; HESSE, 1986, p. 16 et seq., 197 et seq. 
intermediário entre as duas principais rotas de fuga. Essas tentativas mais promissoras podem ser resumidas na fórmula a seguir. O direito não pode assumir plena autoridade epistêmica e responsabilidade pelas construções da realidade envolvidas, mas, ao mesmo tempo, não delega totalmente a autoridade epistêmica a outros discursos sociais. Pelo contrário, como pré-condição à incorporação do conhecimento social, o sistema jurídico define certos requisitos fundamentais relacionados aos procedimentos e métodos de cognição.

Um caso em questão é a decisão do Supremo Tribunal Alemão sobre codeterminação em organizações econômicas ${ }^{116}$. Durante anos, os advogados constitucionais alemães julgaram a constitucionalidade da participação trabalhista com base em seus efeitos econômicos - em termos de eficiência da empresa, desempenho da economia da Alemanha Ocidental e sua posição na competição internacional. Dessa maneira, os atores coletivos envolvidos, ou seja, empresas, associações de empregadores, sindicatos, governo e parlamento, prepararam breves construções de realidade jurídica em seus relatórios, com cenários detalhados sobre as consequências socioeconômicas da codeterminação, apontando consequências catastróficas ou benéficas de acordo com o mais apropriado para suas posições políticas ${ }^{117}$. Além disso, mobilizaram-se especialistas econômicos e sociológicos em ambos os lados.

O tribunal recusou-se a tomar uma posição substantiva sobre esses cenários consequenciais e recorreu a uma solução “processual”: em vez de confirmar ou rejeitar construções de realidade, o tribunal alocou deveres de informação ${ }^{118}$ e deveres de previsão entre os atores coletivos envolvidos, incluindo o próprio tribunal, e criou um novo dever jurídico para o legislador: reverter suas decisões se as previsões em que estavam baseadas se revelassem incorretas ${ }^{119}$.

Em várias decisões mais recentes, essa tendência foi fortalecida: abster-se de construções materiais da realidade e procedimentalizar a solução jurídica; delegar autoridade epistêmica a diferentes atores coletivos, ou seja, agências reguladoras, empresas privadas, sindicatos, instituições de pesquisa, associações de interesse, organizações governamentais, parlamentos, tribunais; alocar deveres de informação e previsão; definir procedimentos e métodos; decidir qual ator coletivo deve

116 Bundesverfassungsgericht, BVerfGE 50, 290.

117 Cf. BADURA; RITTNER; RUTHERS, 1977, p. 137 et seq., 246 et seq.; KÜBLER; SCHMIDT; SIMITIS, 1978, p. 35 et seq., 99 et seq., 145 et seq., 197 et seq.

118 Literalmente, "information risks", "riscos de informação" [N. do T.].

119 Para uma análise aprofundada dessa “procedimentalização” da cognição institucional, ver FREY, 1989, p. 103 et seq.; MAJONE, 1979, 1989; WIETHÖLTER, 1985, 1986, 1989. 
suportar o "ônus da prova” das construções de realidade; e definir responsabilidades para falhas de informação e de previsão ${ }^{120}$.

Até certo ponto, uma perspectiva epistemológica construtivista favoreceria tais tentativas de “procedimentalizar” o conflito entre autonomia epistêmica e heteronomia no direito moderno. De fato, quando as teorias correspondentistas da verdade precisam ser substituídas por teorias consensuais e teorias coerentistas, quando a autoridade da ciência se baseia apenas em seus procedimentos internos de validação, quando sistemas institucionais como o direito são condenados à autonomia epistêmica e não podem recorrer a autoridades externas, a atenção prática e teórica deve se concentrar nos procedimentos que ditam as premissas, o conteúdo e as consequências das construções institucionais da realidade social.

GUNTHER CURT MAX TEUBNER é professor de Direito na Universidade de Bremen e no Instituto Universitário Europeu de Firenze. É autor de numerosos trabalhos em direito e sociedade, incluindo Dilemmas of Law in the Welfare State (1985), Juridification of Social Spheres (1987), Autopoietic Law (1988) e State, Law, Economy as Autopoietic Systems (1990).

\section{REFERÊNCIAS}

\section{ADAMS, Michael. Ökonomische Analyse der Gefährdungs und Verschuldenshaftung.} Heidelberg: Decker and Schenck, 1985.

ALBERT, Hans. Law as an Instrument of Rational Practice. In: DAINTITH, T. C.; TEUBNER, G. (ed.). Contract and Organisation: Legal Analysis in the Light of Economic and Social Theory. Berlin: de Gruyter, 1986.

ALCHIAN, Armen A.; DEMSETZ, H. Production, Information Costs and Economic Organization. In: 62 American Economic Review 777, 1972.

ALEXY, Robert. Theorie der juristischen Argumentation: Die Theorie des rationalen Diskurses als Theorie der juristischen Begründung. Frankfurt: Suhrkamp, 1978.

APEL, Karl-Otto. Das Apriori der Kommunikationsgemeinschaft und die Grundlagen der Ethik. In: APEL, K.-O. Transformation der Philosophic. Frankfurt: Suhrkamp, 1973.

APEL, Karl-Otto. Diskurs und Verantwortung: Das Problem des Übergangs zur postkonventionellen Moral. Frankfurt: Suhrkamp, 1988.

${ }^{120}$ Cf., em direito ambiental, BVerfGE 49, 89; em direito empresarial, BVerfGE 72, 155; em direito de propriedade, BVerfGE 74, 264. 
ARBIB, Michael A.; HESSE, Mary B. The Construction of Reality. Cambridge: Cambridge University Press, 1986.

AUBERT, Vilhelm. In Search of Law: Sociological Approaches to Law. Oxford: Robertson, 1983.

AUBERT, Vilhelm. On the Relationship between Legal and Sociological Concepts. In: BLANKENBURG, E.; ROTTLEUTHNER, H. (ed.). Alternative Rechtsformen und Alternativen zum Recht. Opladen: Westdeutscher Verlag, 1980.

BADURA, Peter; RITTNER, Fritzit; RUTHERS, Bernd. Mitbestimmungsgesetz 1976 und Grundgesetz: Gemeinschaftsgutachten. München: Beck, 1977.

BARNES, Barry. Scientific Knowledge and Sociological Theory. London: Routledge and Kegan, 1974.

BARWISE, Jon; ETCHEMENDY, John. The Liar: An Essay in Truth and Circularity. New York: Oxford University Press, 1987.

BAUDRILLARD, Jean. L’échange symbolique et la mort. Paris: Gallimard, 1976.

BERGER, Peter L; LUCKMANN, Thomas. The Social Construction of Reality: A Treatise in the Sociology of Knowledge. New York: Doubleday, 1966.

BLOOR, David. Knowledge and Social Imagery. London: Routledge and Kegan, 1976.

BOHLER, Dietrich. Rekonstruktive Pragmatik: Von der Bewußtsein philosophie zur Kommunikationsreflexion: Neubegründung der praktischen Wissenschaften und Philosophie. Frankfurt: Suhrkamp, 1985.

BOURDIEU, Pierre. La force du droit: Éléments pour une sociologie du champ juridique. In: Actes de la recherche en sciences sociales 3, 1986.

CARROLL, Lewis. Stanza of Anglo-Saxon Poetry. Misch-Masch, 1855.

CARROLL, Lewis. Through the Looking Glass and What Alice Found There. [Cited after the edition of 1960, Bramhall House, New York]. London: Macmillan, 1871.

CLARK, Robert C. Agency Costs Versus Fiduciary Duties. In: PRATT, J. W.; ZECKHAUSER, R. J. (ed.). Principals and Agents: The Structure of Business. Boston: Harvard Business School Press, 1985.

COHEN, Felix S. Transcendental Nonsense and the Functional Approach. In: 35 Columbia Law Review 809, 1935.

COLLINS, Harry. Changing Order: Replication and Induction in Scientific Practice. Beverly Hills: Sage, 1985.

COTTERRELL, Roger. Law and Sociology: Notes on the Constitution and Confrontation of Disciplines. In: 13 Journal of Law and Society 9, 1986. 
COTTERRELL, Roger. The Sociology of Law: An Introduction. London: Butter-Worths, 1984.

CROZIER, Michel; FRIEDBERG, Erhard. L'acteur et le système: Les contraintes de l'action collective. Paris: Seuil, 1977.

DAN-COHEN, Meir. Rights, Persons, and Organizations: A Legal Theory for Bureaucratic Society. Berkeley: University of California Press, 1986.

DEGGAU, Hans-Georg. The Communicative Autonomy of the Legal System. In: TEUBNER, G. (ed.). Autopoietic Law: A New Approach to Law and Society. Berlin: de Gruyter, 1988.

DOUGLAS, Mary. How Institutions Think. Syracuse, NY: Syracuse University Press, 1986.

DREYFUS, Hubert L; RABINOW, Paul. Michel Foucault: Beyond Structuralism and Hermeneutics. Chicago: University of Chicago Press, 1982.

EASTERBROOK, Frank. Corporations as Contracts. Conference paper, presented at Stanford Law School, 1988.

ELSTER, Jon (ed.). The Multiple Self. Cambridge: Cambridge University Press, 1986.

ELSTER, Jon. Explaining Technical Change. Cambridge: Cambridge University Press, 1983.

ELSTER, Jon. Making Sense of Marx. Cambridge: Cambridge University Press, 1985.

ETZIONI, Amitai. The Moral Dimension: Toward a New Economics. New York: Free Press, 1988.

FAMA, Eugen F.; JENSEN, Michael. Agency, Problems and Residual Claims. In: 26 Journal of Law and Economics 327, 1983.

FEBBRAJO, Alberto. The Rules of the Game in the Welfare State. In: TEUBNER, G. (ed.). Dilemmas of Law in the Welfare State. Berlin: de Gruyter, 1985.

FODOR, J. A. Methodological Solipsism Considered as a Research Strategy in Cognitive Psychology. In: 3 Behavioral Brain Science 63, 1980.

FÖRSTER, Heinz von. Entdecken oder Erfinden? Wie Lußt sich Verstehen Verstehen? In: MOHLAR, A. (ed.). Einführung in den Konstruktivismus. München: Oldenbourg, 1985.

FÖRSTER, Heinz von. Observing Systems. Seaside, CA: Intersystems Publications, 1981.

FOUCAULT, Michel. Discipline and Punish. New York: Vintage/Random House, 1979.

FOUCAULT, Michel. The Archaeology of Knowledge. New York: Harper Colophon, 1972.

FOUCAULT, Michel. The Order of Things: An Archaeology of the Human Sciences. London: Tavistock, 1974. 
FRANKENBERG, Gunter. Der Ernst im Recht. In: 20 Kritische Justiz, p. 281-307, 1987.

FREY, Reiner. Vom Subjekt zur Selbstreferenz: Rechtstheoretische Überlegungen zur Rekonstruktion der Rechtskategorie. Berlin: Duncker and Humblot, 1989.

FULLER, Steve. Social Epistemology. Bloomington: Indiana University Press, 1988.

GIDDENS, Anthony. Social Theory and Modern Sociology. Stanford: Stanford University Press, 1987.

GILBERT, Nigel; MULKAY, Michael. Opening Pandora’s Box. Cambridge: Cambridge University Press, 1984.

GLASERSFELD, Ernst von. An Epistemology for Cognitive Systems. In: ROTH, G.;

SCHWEGLER, H. (ed.). Self-Organizing Systems: An Interdisciplinary Approach. Frankfurt: Campus, 1981.

GLASERSFELD, Ernst von. Konstruktion der Wirklichkeit und des Begriffs der Objektivität. In: GUMIN, H.; MOHLAR, A. (ed.). Einführung in den Konstruktivismus. München: Oldenbourg, 1985.

GLASERSFELD, Ernst von. Radical Constructivism and Piaget's Concept of Knowledge. In: MURRAY, F. B. (ed.). Input of Piagetian Theory. Baltimore: University Park Press, 1975.

GORDON, Robert W. Critical Legal Histories. In: 36 Stanford Law Review 57, 1984.

GRÜNBERGER, Hans. Dehumanisierung der Gesellschaft und Verabschiedung staatlicher Souveränität: Das Politische System in der Gesellschaftstheorie Niklas Luhmanns. In: FETSCHER, I.; MÜNKLER, H. (ed.). Pipers Handbuch der politischen Ideen. München: Piper, 1987.

GRZEGORCZYK, Christophe. Système juridique et réalité: Discussion de la théorie autopoiétique du droit. In: 33 Archives de philosophie du droit, 1989.

GÜNTHER, Klaus. Der Sinn fur Angemessenheit: Anwendungsdiskurse in Moral und Recht. Frankfurt: Suhrkamp, 1988.

HABERMAS, Jürgen. Communication and the Evolution of Society. Boston: Beacon Press, 1974.

HABERMAS, Jürgen. Knowledge and Human Interest. Boston: Beacon Press, 1971a.

HABERMAS, Jürgen. Law as Medium and Law as Institution. In: TEUBNER, G. (ed.). Dilemmas of Law in the Welfare State. Berlin: de Gruyter, 1985.

HABERMAS, Jürgen. Legitimation Crisis. Boston: Beacon Press, 1975.

HABERMAS, Jürgen. Moralbewußtsein und kommunikatives Handeln. Frankfurt: Suhrkamp, 1983. 
HABERMAS, Jürgen. Nachmetaphysisches Denken: Philosophische Aufsätze. Frankfurt: Suhrkamp, 1988.

HABERMAS, Jürgen. The Theory of Communicative Action. Lifeworld and System: A Critique of Functionalist Reason. V. 2. Boston: Beacon Press, 1987a.

HABERMAS, Jürgen. The Theory of Communicative Action. V. 1: Reason and the Rationalization of Society. Boston: Beacon Press, 1984.

HABERMAS, Jürgen. Vorbereitende Bemerkungen zu einer Theorie der kommunikativen Kompetenz. In: HABERMAS, J.; LUHMANN, N. Theorie der Gesellschaft oder Sozialtechnologie — Was leistet die Systemforschung. Frankfurt: Suhrkamp, 1971b.

HABERMAS, Jürgen. Wahrheitstheorien. In: FAHRENBACH, H. (ed.). Wirklichkeit und Reflexion. Pfullingen: Neske, 1973.

HABERMAS, Jürgen. Wie ist Legitimation durch Legalität möglich? In: 20 Kritische Justiz 1, $1987 b$.

HAYEK, Friedrich A. Individualism and Economic Order. London: Routledge, 1948.

HAYEK, Friedrich A. Law, Legislation, and Liberty, Vol. 1: Rules and Order. London: Routledge and Paul, 1973.

HELLER, Thomas. Accounting for Law. In: TEUBNER, G. (ed.). Autopoietic Law: A New Approach to Law and Society. Berlin: de Gruyter, 1988.

HELLER, Thomas. Structuralism and Critique. In: 36 Stanford Law Review 127, 1984.

HOMANS, George C. Social Behavior: Its Elementary Forms. London: Routledge and Kegan, 1961.

HONNETH, Axel. Kritik der Macht: Reflexionsstufen einer kritischen Gesellschaftstheorie. Frankfurt: Suhrkamp, 1985.

HORWITZ, Morton. Santa Clara Revisited. In: 88 West Virginia Law Review 173, 1985.

HUTTER, Michael. Die Produktion von Recht. Tübingen: Mohr und Siebeck, 1989.

JHERING, Rudolf von. Scherz und Ernst in der Jurisprudenz. Leipzig: Breitkopf und Haertel, 1884.

JOERGES, Christian. Politische Rechtstheorie and Critical Legal Studies. In: JOERGES, C.; TRUBEK, D. (ed.). Critical Legal Thought: An American-German Debate. Baden-Baden: Nomos, 1989.

KENNEDY, David. Critical Theory, Structuralism, and Contemporary Scholarship. In: 21 New England Law Review 209, 1985. 
KENNEDY, Duncan. Freedom and Constraint in Adjudication: A Critical Phenomenology. In: 36 Journal of Legal Education 518, 1986.

KERCHOVE, Michel van de; OST, François. Le système juridique entre ordre et desordre. Paris: Presses Universitaires de France, 1988.

KITSCHELT, Herbert. Der ökologische Diskurs: Eine Analyse von Gesellschaftskonzeptionen in der Energiedebatte. Frankfurt: Campus, 1984.

KNORR-CETINA, Karin. Die Fabrikation von Erkenntnis: Zur Anthropologic der Naturwissenschaft. Frankfurt: Suhrkamp, 1984.

KNYPHAUSEN, Dodo zu. Unternehmungen als evolutionsfähige Systeme: Überlegungen zu einem evolutionären Konzept für die Organisationstheorie. Herrsching: Kirsch, 1988.

KRIPPENDORFF, Klaus. Paradox and Information. In: DERVIN, B.; VOIGHT, M. (ed.). Progress in Communication. Norwood: Ablex, 1984.

KÜBLER, Friedrich; SCHMIDT, Walter; SIMITIS, Spiros. Mitbestimmung als gesetzgebungspolitische Aufgabe. Baden-Baden: Nomos, 1978.

LADEUR, Karl-Heinz. Zu einer Grundrechtstheorie der Selbstorganisation des Unternehmens. In: Festschrift fur Helmut Ridder. Neuwied: Luchterhand, 1989b.

LADEUR, Karl-Heinz. Abwägung-Ein neues Paradigma des Verwaltungsrechts: Von der Einheit der Rechtsordnung zum Rechtspluralismus. Frankfurt: Campus, 1984.

LADEUR, Karl-Heinz. Perspectives on a Post-Modern Theory of Law. In: TEUBNER, G. (ed.), Autopoietic Law: A New Approach to Law and Society. Berlin: de Gruyter, 1988.

LADEUR, Karl-Heinz. The Law of Uncertainty. In: JOERGES, C.; TRUBEK, D. (ed.). Critical Legal Thought: An American-German Debate. Baden-Baden: Nomos, 1989a.

LATOUR, Bruno; WOOLGAR, Steve. Laboratory Life: The Construction of Scientific Facts. Princeton: Princeton University Press, 1979.

LÜBBE-WOLFF, Gertrude. Rechtsfolgen und Realfolgen. Freiburg: Alber, 1981.

LUHMANN, Niklas. Closure and Openness: On Reality in the World of law. In: TEUBNER, G. (ed.). Autopoietic Law: A New Approach to Law and Society. Berlin: de Gruyter, 1988a.

LUHMANN, Niklas. Die Autopoiese des Bewußtseins. In: 36 Sociale Welt 402, 1985.

LUHMANN, Niklas. Individuum und Gesellschaft. In: 39 Universitas 1, 1983.

LUHMANN, Niklas. Intersubjektivitat oder Kommunikation: Unterschiedliche Ausgangspunkte soziologischer Theoriebildung. In: 54 Archivio di Filosofia 41, 1986c.

LUHMANN, Niklas. Rechtssystem und Rechtsdogmatik. Stuttgart: Kohlhammer, 1974. 
LUHMANN, Niklas. Soziale Systemme: Grundriß einer allgemeinen Theorie. Frankfurt:

Suhrkamp, 1984.

LUHMANN, Niklas. The Autopoiesis of Social Systems. In: GEYER, F.; ZOUWEN, J. van der (ed.). Sociocybernetic Paradoxes. London: Sage, 1986a.

LUHMANN, Niklas. The Coding of the Legal System. In: FEBBRAJO, A.; TEUBNER, G. (ed.). State, Law, Economy as Autopoietic Systems. Milano: Giuffrè, 1990.

LUHMANN, Niklas. The Individuality of the Individual: Historical Meaning and Contemporary Problems. In: HELLER, T. C.; SOSNA, M.; WELLBERY, D. E. (ed.). Reconstructing

Individualism: Autonomy, Individuality, and the Self in Western Thought. Stanford, CA: Stanford University Press, 1986b.

LUHMANN, Niklas. The Theory of Social Systems and Its Epistemology: Reply to Danilo Zolo's Critical Comments. In: 16 Philosophy of the Social Sciences, p. 129-134, 1985.

LUHMANN, Niklas. The Third Question: The Creative Use of Paradoxes in Law and Legal History. In: 15 Journal of Law and Society 153, 1988b.

LUHMANN, Niklas. Wissenschaft. Bielefeld: Typoscript, 1988c.

MAJONE, Giandomenico. Evidence, Argument and Persuasion in the Policy Process. New Haven: Yale University Press, 1989.

MAJONE, Giandomenico. Process and Outcome in Regulatory Decision-Making. In: WEISS, C. H.; BARTON, A. (ed.). Making Bureaucracies Work. Beverly Hills: Sage, 1979.

MATURANA, Huberto R.; VARELA, Francisco J. Autopoiesis and Cognition. Boston: Reidel, 1980.

MAYNTZ, Renate. Steuerung, Steuerungsakteure und Steuerungsinstrumente: Zur Präzisierung des Problems. In: 70 HiMon-DB. Siegen: Universität, 1986.

MENGONI, Luigi. La questione del ‘diritto giusto’ nella società postliberale. In: 11

Fenomenologia e Società Diritto ed Etica Pubblica 14, 1988.

NELSON, Alan. Some Issues Surrounding the Reduction of Macroeconomics to Microeconomics. In: 51 Philosophy of Science 573, 1984.

NERHOT, Patrick. The Fact of Law. In: TEUBNER, G. (ed.). Autopoietic Law: A New Approach to Law and Society. Berlin: de Gruyter, 1988.

OPP, Karl-Dieter. Soziologie im Recht. Reinbek: Rowohlt, 1973.

OST, François. Between Order and Disorder: The Game of Law. In: TEUBNER, G. (ed.). Autopoietic Law: A New Approach to Law and Society. Berlin: de Gruyter, 1988.

PIAGET, Jean. The Construction of Reality in the Child. New York: Ballantine, 1971. 
PIZZORNO, Alessandro. Spiegazione come re-identificatione. In: SCIOLLA, L.; RICOLFI, L. (ed.). Il soggetto dell'azione: Paradigmi sociologichi e immagini dell'attore sociale. Milano: Angeli, 1989.

PODAK, Klaus. Ohne Subjekt, ohne Vernunft: Bei der Lektüre von Niklas Luhmanns Hauptwerk 'Soziale Systeme’. In: 7 Merkur 733, 1984.

POPPER, Karl. The Poverty of Historicism. London: Routledge and Kegan Paul, 1953.

PREUSS, Ulrich K. Rationality Potentials of Law: Allocative, Distributive and Communicative Rationality. In: JOERGES, C.; TRUBEK, D. (ed.). Critical Legal Thought: An American-German Debate. Baden-Baden: Nomos, 1989.

PRINS, H. Offenders, Deviants or Patients? An Introduction to the Study of Socio-Forensic Problems. London: Tavistok, 1980.

QUINE, Willard V. The Ways of Paradox. Cambridge, MA: Harvard University Press, 1976.

ROOS, Carl Martin. Corporate Personality and Contractual Structure: Legal Aspects on the Firm as a Nexus of Treaties. Uppsala: Manuscript, 1988.

ROTH, Gerhard. Die Entwicklung kognitiver Selbstreferentialität im menschlichen Gehirn. In: BAECKER, D. et al. (ed.). Theorie als Passion. Frankfurt: Suhrkamp, 1987.

ROTH, Gerhard. Erkenntnis und Realität: Das Gehirn und seine Wirklichkeit. In: PASTERNACK, G. (ed.). Erklären, Verstehen, Begründen. Bremen: Universitat, 1984.

ROTTLEUTHNER, Hubert. Biological Metaphors in Legal Thought. In: TEUBNER, G. (ed.). Autopoietic Law: A New Approach to Law and Society. Berlin: de Gruyter, 1988.

ROTTLEUTHNER, Hubert. Diskussionsvotum zum vorstehenden Beitrag. In: BLANKENBURG, E.; KLAUSA, E; ROTTLEUTHNER, H. (ed.). Alternative Rechtsformen und Alternativen zum Recht. Opladen: Westdeutscher Verlag, 1980.

ROTTLEUTHNER, Hubert. Zur Methode einer folgenorientierten Rechtsanwendung. In: Archiv für Rechts- und Sozialphilosophie, Beiheft 13. Wiesbaden: Steiner, 1979.

SCHANE, Sanford A. The Corporation is a Person: The Language of a Legal Fiction. In: 61 Tulane Law Review 563, 1987.

SCHANZE, Erich. Contract, Agency, and the Delegation of Decision Making. In: BAMBERG, G.; SPREMAN, K. (ed.). Agency Theory, Information, and Incentives. Berlin: Springer, 1987.

SCHANZE, Erich. Potential and Limits of Economic Analysis: The Constitution of the Firm. In: DAINTITH, T.; TEUBNER, G. (ed.). Contract and Organisation: Legal Analysis in the Light of Economic and Social Theory. Berlin: de Gruyter, 1986. 
SCHIMANK, Uwe. Der mangelnde Akteurbezug systemtheoretischer Erklärungen gesellschaftlicher Differenzierung-Ein Diskussionsvorschlag. In: 14 Zeitschrift für Soziologie 421, 1985.

SCHMIDT, Siegfried (ed.). Der Diskurs des Radikalen Konstruktivismus. Frankfurt: Suhrkamp, 1987.

SCOTT, Robert. The Jabberwock Traced to Its True Source. Macmillan's Magazine, February 1872.

SELZNICK, Philip. Law: The Sociology of Law. In: 9 International Encyclopedia of the Social Sciences 50, 1968.

SKINNER, Quentin. The Return of Grand Theory in the Human Sciences. Cambridge, England: Cambridge University Press, 1985.

TEUBNER, Gunther. And God Laughed...: Indeterminacy, Self-Reference, and Paradox in Law. In: JOERGES, C.; TRUBEK, D. (ed.). Critical Legal Thought: An American-German Debate. Baden-Baden: Nomos, 1989.

TEUBNER, Gunther. Enterprise Corporatism: New Industrial Policy and the 'Essence' of the Legal Person. In: 36 American Journal of Comparative Law 130, 1988a.

TEUBNER, Gunther. Evolution of Autopoietic Law. In: TEUBNER, G. (ed.). Autopoietic Law: A New Approach to Law and Society. Berlin: de Gruyter, 1988b.

TEUBNER, Gunther. Generalklauseln als sozio-normative Modelle. In: STACHOWIAK, H. (ed.).

Bedürfnisse, Werte und Normen im Wandel. Bd1. München: Fink and Schöningh, 1982.

TEUBNER, Gunther. Hypercycle in Law and Organization: The Relationship between SelfObservation, Self-Constitution and Autopoiesis. In: European Yearbook in the Sociology of Law 43, 1988c.

TEUBNER, Gunther. Social Order from Legislative Noise? Autopoietic Closure as a Problem for Legal Regulation. In: TEUBNER, G.; FEBBRAJO, A. (ed.). State, Law, Economy as Autopoietic Systems. Milano: Giuffrè, 1990.

VARDARO, Gaetano. Before and Beyond the Legal Personality: Group Enterprises and Industrial Relations. In: SUGARMAN, D.; TEUBNER, G. (ed.). Regulating Corporate Groups in Europe. Baden-Baden: Nomos, 1990.

VARELA, Francisco J. Living Ways of Sense-Making: A Middle Path for Neuro-Science. In: LIVINGSTONE, P. (ed.). Disorder and Order: Proceedings of the Stanford International Symposium. Saratoga, CA: Anma Libri, 1984.

WEBER, Max. Economy and Society. Berkeley: University of California Press, 1978.

WEINBERG, Alvin M. Science and Trans-science. In: 10 Minerva 209, 1972. 
WEINTRAUB, E. Roy. Microfoundations: The Compatibility of Microeconomics and Macroeconomics. Cambridge: Cambridge University Press, 1979.

WIETHÖLTER, Rudolf. Proceduralization of the Category of Law. In: JOERGES, C.; TRUBEK, D. (ed.). Critical Legal Thought: An American-German Debate. Baden-Baden: Nomos, 1989.

WIETHÖLTER, Rudolf. Social Science Models in Economic Law. In: DAINTITH, T.; TEUBNER, G. (ed.). Contract and Organisation: Legal Analysis in the Light of Economic and Social Theory. Berlin: de Gruyter, 1986.

WIETHÖLTER, Rudolf. Materialization and Proceduralization in Modern Law. In: TEUBNER, G. (ed.). Dilemmas of Law in the Welfare State. Berlin: de Gruyter, 1985.

WILLIAMSON, Oliver E. The Contractual Logic of Internal Organization. Firenze: EUI conference paper, 1987.

WINDSCHEID, Bernhard. Die Aufgaben der Rechtswissenshaft. In: WINDSCHEID, B. Gesammelte Reden und Abhandlungen. Leipzig: Duncker, 1904.

WINTER, Gert. Die Angst des Richters bei der Technikbewertung. In: 20 Zeitschrift fur Rechtspolitik 425, 1987.

WOLF, Rainer. Der Stand der Technik. Opladen: Westdeutscher Verlag, 1986.

WORMELL, C. P. On the Paradoxes of Self-Reference. In: 67 Mind 267, 1958. 